\title{
Gene profiling of the erythro- and megakaryoblastic leukaemias induced by the Graffi murine retrovirus
}

\author{
Veronique Voisin ${ }^{1,2}$, Philippe Legaultt, Diana Paulina Salazar Ospina ${ }^{1}$, Yaacov Ben-David ${ }^{2}$, Eric Rassart ${ }^{1 *}$
}

\begin{abstract}
Background: Acute erythro- and megakaryoblastic leukaemias are associated with very poor prognoses and the mechanism of blastic transformation is insufficiently elucidated. The murine Graffi leukaemia retrovirus induces erythro- and megakaryoblastic leukaemias when inoculated into NFS mice and represents a good model to study these leukaemias.
\end{abstract}

Methods: To expand our understanding of genes specific to these leukaemias, we compared gene expression profiles, measured by microarray and RT-PCR, of all leukaemia types induced by this virus.

Results: The transcriptome level changes, present between the different leukaemias, led to the identification of specific cancerous signatures. We reported numerous genes that may be potential oncogenes, may have a function related to erythropoiesis or megakaryopoiesis or have a poorly elucidated physiological role. The expression pattern of these genes has been further tested by RT-PCR in different samples, in a Friend erythroleukaemic model and in human leukaemic cell lines.

We also screened the megakaryoblastic leukaemias for viral integrations and identified genes targeted by these integrations and potentially implicated in the onset of the disease.

Conclusions: Taken as a whole, the data obtained from this global gene profiling experiment have provided a detailed characterization of Graffi virus induced erythro- and megakaryoblastic leukaemias with many genes reported specific to the transcriptome of these leukaemias for the first time.

\section{Background}

Human acute megakaryoblastic (FAB-AML7, [1]) and erythroleukaemias (FAB-AML6, [2]) are regarded as relatively rare entities of acute myeloid leukaemia but are associated with a very poor prognosis [3-7]. The poor outcome linked to these 2 types of leukaemias stems from a combination of failure to achieve complete remission, a high relapse rate and therapy-related toxicity, highlighting the need for more powerful therapies. Furthermore, AML6 or AML7 diagnosis represents a greater challenge than other types of acute myeloid leukaemia (AML) and additional markers are needed [8]. Furthermore, the blasts of patients with AML6 and AML7 share common markers [9] indicating that they

\footnotetext{
* Correspondence: rassart.eric@uqam.ca

'Laboratoire de Biologie Moléculaire, Département des Sciences Biologiques, Centre BioMed, Université du Québec à Montréal, Case Postale 8888 Succursale Centre-ville, Montréal, QC, H3C-3P8, Canada
}

originate from closely related haematopoietic lineages derived from a common bipotent progenitor $[10,11]$.

We have recently shown that the murine retrovirus Graffi is able to induce a broad spectrum of leukaemias when inoculated into newborn mice. The leukaemias developed by these mice are of lymphoid ( $\mathrm{T}$-cell and B-cell) and non lymphoid (myeloid, erythroid and megakaryoblastic) origins. The incidence of erythro- and megakaryoblastic leukaemias is particularly high in NFS or $\mathrm{FVB} / \mathrm{n}$ mice inoculated with the GV-1.4 variant of the Graffi virus [12]. The activation of the targeted proto-oncogene or the repression of tumor suppressor genes represents early events in the development of the murine leukaemia retrovirus (MuLV) induced leukaemia. It is then followed by a deregulation of numerous additional genes resulting in a cell, blocked at a very immature stage, which aggressively divides and escapes apoptosis. To analyze these cancerous signatures, we 
compared the gene profiles of each type of leukaemia (T-cell, B-cell, myeloid, erythroid, megakaryoblastic) induced by the Graffi virus. These analyses highlight many genes that may be potential oncogenes and may have a function related to erythropoiesis or megakaryopoiesis. The results support the importance of the known transcription factors Gata1, Fogl, Fli1, Scl and Lmo2 in both erythro- and megakaryoblastic leukaemias and the role of Runx1, Pbxi, Meis, Evi1 and Evi3 in the megakaryoblastic leukaemias. Moreover, numerous genes are being reported for the first time and some of these genes are candidate oncogenes: Fgf3, Nmyc, Fap, Myct1, Gucy1a3, Gulp1 and Fkbp9 specific to megakaryoblastic leukaemias and Ssx2ip, Rab11a, Ncoa3, Snca, Ltbp2, Rabgef1 and Btbd14a specific to erythroleukaemias. A screening for viral integrations was performed in mouse tumors. Several genes, amongst which Kit, Gata2, Irf8 and Itga1, were identified as potentially implicated in the onset development of the megakaryoblastic leukaemias.

\section{Methods}

\section{Virus production and mice}

GV-1.4 viral stock was made as previously described [12]. GV-1.4 viral particles $\left(0.1 \mathrm{ml}\right.$ at a titer of $\left.1.10^{6} \mathrm{PFU} / \mathrm{ml}\right)$ were injected into 1 day newborn NFS mice. The mice were checked routinely for clinical signs of disease and moribund mice were sacrificed. Twenty-four diseased mice and 36 control mice were used for the microarray and RT-PCR experiments. Bone marrow cell suspension was prepared by flushing the femurs with IMDM $2 \%$ foetal bovine serum (FBS) and spleen cell suspension was prepared by mincing the spleen with scissors and aspirating the pieces up and down through a $1 \mathrm{cc}$ syringe in IMDM $2 \%$ FBS. The spleen and bone marrow cell suspensions were filtered through $70 \mu \mathrm{m}$ cell strainers (Becton Dickson, Mississauga, Canada). All the experimental procedures are conformed to the Helsinki Declaration and were approved by the Animal Care and Use Committees of Université du Québec à Montréal.

\section{Flow cytometry analyses and cell sorting}

The flow cytometry staining procedure was performed as previously described [12]. The antibodies used were as follows: CD4, CD8a, CD3, CD90, CD19, B220, CD11b, Gr1, CD71, Ter119, CD41, Kit and Sca1 (BD Pharmingen, Mississauga, Canada). The leukaemic populations were isolated from the haematopoietic organs by positive selection using magnetic beads with the EasySep Kit (StemCell Technologies, Vancouver, Canada) according to the manufacturer's protocol. The rates of purity and viability of the sorted cells were fixed to be equal to or greater than $95 \%$. Leukaemic T-cells were sorted from the thymus of leukaemic NFS mice, B-cell from the enlarged lymph nodes and erythro- and megakaryoblastic leukaemic cells were sorted from the infiltrated spleen. Control cells were sorted from the haematopoietic organs of 12 pooled non-infected NFS mice: T-cells were obtained from the thymus, B-cells from the spleen, and erythroblasts from the bone marrow.

\section{RNA extraction and microarray processing}

Total RNA was extracted from the sorted cell populations with Trizol reagent (Invitrogen, Burlington, Canada) followed by column purification using the Qiagen RNeasy Kit (QIAGEN, Mississauga, Canada) and processed for hybridization to Affymetrix GeneChip ${ }^{\circ}$ Mouse Genome 4302.0 arrays (Genome Quebec Innovation Centre, Montreal, Canada).

\section{Data analysis}

Data Set Normalization: Affymetrix MicroArray Suite version 5.0 was used to scan and quantify the arrays. Normalization of gene expression data were performed using the Bioconductor implementation of RMA (Robust Multi Array, B. Bolstad, University of California, Berkeley) available from the Flexarray software (1.2, R 2.7.2, [13]).

Unsupervised learning: Hierarchical clustering (complete linkage clustering, correlation uncentered, [14]) and Self-Organization Maps (SOM, parameters G 1-5, A $1-10,[15])$ were constructed using GeneCluster software (M. Eisen). 3,000 transcripts were selected to be included in the analyses based on the differential expression from the mean. The deviation from the mean was calculated from the RMA values of the 45,000 probesets and the data were ranked in decreasing order to extract the first 3,000 genes. Only deviations equal or above 0.585 (1.5 fold change) and equal or below -0.585 (-1.5 fold change) were considered as significant.

Supervised learning: Significance Analysis of microarrays (SAM, [16]). SAM analyses were performed using Flexarray software using the normalized data of the 45,000 probesets. Data with p-values equal or below 0.01 and False Discover Rates (Benjamini Hochberg) equal or below 0.20 were included in further analyses. The data were ranked in decreasing order of the SAM d-score to obtain the list of the differentially expressed genes.

The NetAffx website (Affymetrix, Santa Clara, CA, USA) was used to retrieve gene ontology (GO) annotations, probe sequences, and was utilized as a link to Unigene (NCBI) for further functional studies.

The microarray dataset was deposited at Gene Expression Omnibus under accession number [GSE12581].

\section{Cell line and differentiation assay}

The murine erythroleukaemic cell line HB22.2 was obtained from murine erythroblasts infected with Friend 
Murine Leukaemia Virus (F-MuLV) [17]. This cell line was maintained in alpha minimum essential medium $(\alpha-M E M)$ supplemented with $10 \%$ (FBS) (Invitrogen, Frederick, MD) plus a penicillin/streptomycin cocktail. To induce differentiation, HB22.2 cells were incubated in the presence of hemin (Sigma-aldrich H5533) at a concentration of $100 \mu \mathrm{M}$. The cells were harvested 24 hours and 72 hours after addition of hemin. K562 (ATCC, USA), HEL (ATCC, USA), Jurkat (ATCC, USA) and Tk6 (ATCC, USA) cells were grown in RMPI supplemented with $10 \%$ FBS plus a penicillin/streptomycin cocktail. MEG-01 (ATCC, USA), CMK (DSMZ, Germany) and LAMA84 (DSMZ, Germany) cells were grown in RPMI supplemented with $20 \%$ FBS plus a penicillin/streptomycin cocktail with a concentration of $10^{5}$ cells $/ \mathrm{ml}$.

\section{RT-PCR}

Oligo $\mathrm{d}(\mathrm{T})$ primed reverse transcription was performed using Omniscript Reverse Transcriptase (QIAGEN, Mississauga, Canada) in a $20 \mu \mathrm{l}$ reaction volume $\left(42^{\circ} \mathrm{C}, 1 \mathrm{~h}\right)$ by taking equal amounts of RNA (100 ng) from the Graffi-leukaemic cells and the murine HB22.2 cell line. cDNA $(4 \mu \mathrm{l})$ was amplified using Taq polymerase (QIAGEN, Mississauga, Canada) at $94^{\circ} \mathrm{C}$ for $5 \mathrm{~min}, 72^{\circ} \mathrm{C}$ for $45 \mathrm{~s}, 57^{\circ} \mathrm{C}$ for $45 \mathrm{~s}, 72^{\circ} \mathrm{C}$ for $45 \mathrm{~s}, 72^{\circ} \mathrm{C}$ for $10 \mathrm{~min} .25$ and 28 cycles were used for the Graffi-leukaemic cells and 27 cycles were used for the HB22.2 cell line. $0.01 \mu \mathrm{l}$ of cDNA and 25 cycles were used to amplify ubiquitously expressed $\beta$-actin and Gapdh genes. cDNA from the human haematopoietic cell lines was amplified using $500 \mathrm{ng}$ of total RNA and the PCR reactions were performed using $4 \mu \mathrm{l}$ of cDNA and 30 PCR cycles. Ubiquitously expressed human GAPDH gene was amplified using $0.01 \mu \mathrm{l}$ of cDNA and 25 cycles. The primer sets are listed in supplementary data (Additional file 1). PCR products were analyzed on $2 \%$ agarose gels containing $0.5 \mu \mathrm{g} / \mathrm{ml}$ ethidium bromide. The gels were scanned (Molecular Dynamics Phosphorimager) and the density of the RT-PCR bands were assessed using the Quantity One software.

\section{Amplification of retroviral integration sites}

This protocol was adapted from A. Berns and colleagues [18]. Tumor DNA from the spleen $(10 \mu \mathrm{g})$ was digested with BamHI (New England Biolabs, Pickering, Canada). A splinkerette adaptor was generated by annealing 2 oligonucleotides (5'CATGGGCTAAAGAGGACTAATAACAAGCGTGGCTGAATGAGACTGGTGTCGA CACTAGTGG3', 5'GATCCCACTAGTGTCGACACCAGTCTCTAATTTTTTTTTTC AAAAAAA3', $95^{\circ} \mathrm{C} 5 \mathrm{~min}$, cool-down to room temperature). $1 \mu \mathrm{g}$ of digested DNA was ligated to the splinkerette oligonucleotide (molar ratio DNA/splinkerette 1:10) using a T4 DNA ligase (New
England Biolabs, Pickering, Canada). The ligated product was then digested with ClaI (New England Biolabs, Pickering, Canada). A PCR followed by a nested PCR (150 ng of the ligated product) were performed using a primer located in the Graffi virus U3 sequence (5'GGTCTCTTGAAA-CTGCTGAGGG 3' and 5'GACCTTGATCTGAACTT-CCCTATTC3') and one corresponding to the splinkerette oligonucleotide. The PCR program was the following: $94^{\circ} \mathrm{C}$ for $1 \mathrm{~min}, 68^{\circ} \mathrm{C}$ for $30 \mathrm{~s}$ (2 cycles), $94^{\circ} \mathrm{C}$ for $15 \mathrm{~s}, 58^{\circ} \mathrm{C}$ for $30 \mathrm{~s}, 72^{\circ} \mathrm{C} 3 \mathrm{~min}(27$ cycles $), 72^{\circ} \mathrm{C} 10 \mathrm{~min}$. The PCR products were cloned (PCR Cloning Kit, Qiagen, Mississauga, Canada,) and sent for sequencing (Genome Quebec Innovation Centre, Montreal, Canada). The sequences were subjected to BLAST analysis against the annotated mouse genome database using Ensembl Genome Browser (release 45).

\section{Results}

Erythro- and megakaryoblastic leukaemias induced by the murine Graffi retrovirus and hybridization on microarrays

NFS newborn mice inoculated with the Graffi murine retrovirus develop an average of $20 \%$ of erythroleukemia and $20 \%$ of megakaryoblastic leukemias with a latency of about 148 days [12]. These mice suffer from severe anaemia and hepatosplenomegaly. The erythroleukaemic cells, Ter $119^{+} \mathrm{CD} 71^{+}$, and the megakaryoblastic leukaemic cells, CD $41^{+} \mathrm{Kit}^{+}$or $\mathrm{CD} 41^{-} \mathrm{Kit}^{+}$, are mainly found in the bone marrow and spleen of the diseased mice [12]. As opposed to Graffi-lymphoid leukaemias, the presence of blast cells is rare in blood smears of both erythroand megakaryoblastic leukaemias, consistent with clinical data on human acute erythroleukaemia [8].

To gain insight into the cancerous signatures of the different leukaemias induced by Graffi MuLV, microarray experiments were designed to compare the expression signature of genes from each type of leukaemia. Cells from the infiltrated haematopoietic organs of the leukaemic mice were isolated (Additional file 2) and subjected to microarray analysis. Unsupervised learning methods, hierarchical clustering, and SOM analyses were used to uncover the primary pattern in the data (Figure 1). Altogether, four distinct gene clusters representing T-cells (T), B-cells (B), megakaryoblastic/myeloid cells $(\mathrm{Mk} / \mathrm{M})$ and erythroid cells $(\mathrm{E})$ emerged from the clustering (Figure 1A).

A more detailed SOM analysis performed on the erythroid and megakaryoblastic genes further classified them into 3 major signatures: erythroid-megakaryoblastic EMk (19\%), erythroid E (42\%) and megakaryoblastic Mk (39\%) (Figure 1B). E and Mk represent the genes over-expressed in the erythro- and megakaryoblastic leukaemias, respectively, and EMk represents the genes specifically over-expressed in both types. MkE1 indicates genes over-expressed in the 3 megakaryoblastic 


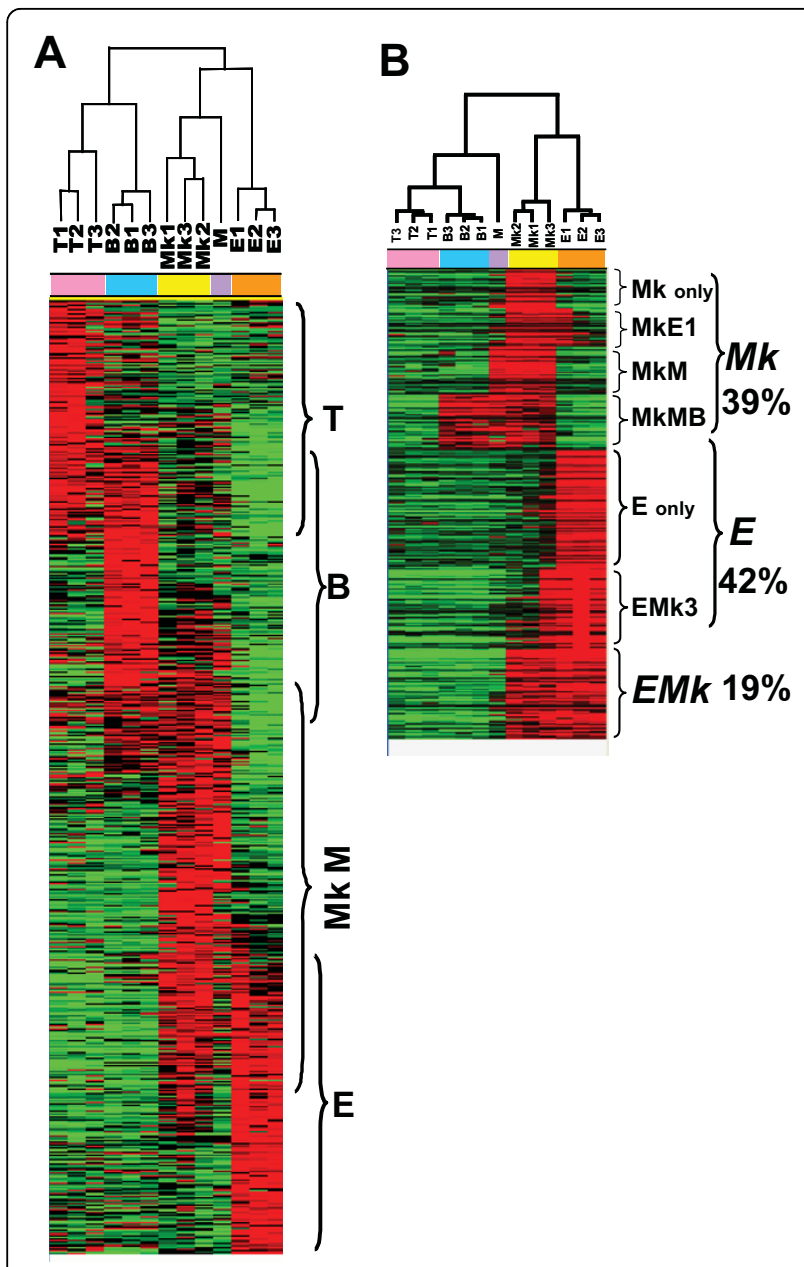

Figure 1 Hierarchical clustering and data scatter. (A) Heat map of the hierarchical clustering and SOM analyses of all data. (B) Heat map of the clustering and SOM analyses of the erythroid and megakaryoblastic over-expressed genes. Each column represents a leukaemia (T-cell: T1, T2, T3; B-cell: B1, B2, B3; Myeloid: M; Erythroid: E1, E2, E3; Megakaryoblastic: Mk1, Mk2, Mk3) and each row is assigned to a transcript. A red colour means a positive deviation of 0.595 and above from the mean (over-expression) and a green colour means a negative deviation of -0.595 and below from the mean (under-expression). The black colour corresponds to values comprised between 0.595 and -0.595 . The result of the clustering on the arrays is shown as a dendrogram on the top of the figure. The nodes of the tree indicate the degrees of similarity between the leukaemias.

leukaemias (Mk1-Mk3) and the erythroleukaemia E1. Similarly, EMk3 corresponds to genes over-expressed in 3 erythroleukaemias (E1-E3) and the megakaryoblastic leukaemia Mk3. These results indicate that the leukaemias E1 and Mk3 are biphenotypic and express both erythroid and megakaryoblastic markers, which was previously observed in some Graffi-induced erythro- and megakaryoblastic leukaemias [12]. The MkMB signature includes genes over-expressed in megakaryoblastic leukaemias (Mk1-Mk3), myeloid leukaemia (M) and B-cell leukaemias (B1-B3). A detailed analysis of Mk, E and EMk signatures has revealed that many of the genes have not yet been reported in relation to the erythroid or the megakaryocytic lineages or to the corresponding leukaemias. The complete lists of genes detailing these non-lymphoid signatures are publicly available at http:// www.biomed.uqam.ca/rassart/microarray.html[19].

The lineage specific expression of genes involved in heme biosynthesis, the megakaryocytic fibrinogen receptors and the expression of well known transcription factors validate the true lineage of these erythro- and megakaryoblastic leukaemias (Table 1).

\section{The megakaryoblastic signature}

The megakaryoblastic specific genes assigned with a functional annotation (GO terms) were divided into different functional classes. Table 2 lists some genes potentially implicated in the disease but the complete data are readily available [19]. Within this list of genes, the oncogenes Meis1 (Myeloid ecotropic viral integration site 1), Pbx1 (Pre B-cell leukaemia transcription factor 1), Evi1 (ecotropic viral integration site 1), Evi3 (Zfp521, zinc finger protein 521) and the co-repressor Cbfa2t3h (Corebinding factor, runt domain, alpha subunit 2, translocated to, 3 (human), Eto2) have already been related to megakaryoblastic leukaemias or megakaryocytic lineage [20-25].

However, several other genes, for example Nmyc (Neuroblastoma myc-related oncogene 1), Fgf3 (Fibroblast growth factor 3) and Fap (Fibroblast activation protein), that are also known oncogenes [26-29], have never been reported with megakaryoblastic leukaemias. Myct1 (Myc target 1) is also potentially implicated in the disease as it is positively regulated by $M y c$ and contains tumorigenic properties by itself [30].

Among the list of genes identified as the MkMB signature, we found Jun (Jun oncogene), Fosl2 (Fos-like antigen 2) and Fes (Feline sarcoma oncogene) (Table 2, $[31,32]$ ). The co-repressor Ctbp2 (C-terminal binding protein 2), Sfpi1 (SFFV proviral integration 1, PU.1) and Kit (Kit oncogene) are also MkMB signature elements. Ctbp2 is known to interact with Evil and Fog [33]. Sfpi1 was shown to regulate the expression of the integrin $\alpha I I b$ (Itga2B, CD41) in a TPO-induced Mpl-UT7 model $[34,35]$ and it was reported as an insertional target of the Graffi MuLV [36].

Due to technical limitations, no megakaryoblastic control was present in our study. Normal megakaryocytes and therefore megakaryoblasts represent a minor population in normal mice and it was not possible to obtain enough purified cells with the technique utilized for other samples. We therefore compared our dataset to a study of murine megakaryocytic maturation indicating up- or down-regulation during differentiation (dataset GSE6593, [37]). 
Table 1 Genes specific to the erythroid and megakaryoblastic leukaemias

\begin{tabular}{|c|c|c|c|c|c|c|c|c|c|c|c|c|c|c|c|c|}
\hline \multirow[t]{2}{*}{ probeset } & \multirow[t]{2}{*}{ gene } & \multicolumn{2}{|c|}{ SAM results * } & \multicolumn{13}{|c|}{ Leukaemic samples** } \\
\hline & & d-score & & $\mathrm{T} 1$ & $\mathrm{~T} 2$ & T3 & B1 & B2 & B3 & M & E1 & E2 & E3 & Mk1 & MK2 & Mk3 \\
\hline \multicolumn{17}{|c|}{ Fibrinogen receptor and related genes } \\
\hline 1417758_at & $\operatorname{ltg} a 2 b$ & 10.58 & $<0.001$ & -2.7 & -1.6 & -2.6 & -2.9 & -2.6 & -2.7 & -1.6 & 3.8 & 0.8 & 1.1 & 3.6 & 3.6 & 3.8 \\
\hline 1421511_at & $\operatorname{ltg} 63$ & - & $>0.01$ & -1.0 & -0.7 & -0.7 & -0.8 & -0.7 & -0.9 & -0.6 & 1.6 & -0.7 & -0.7 & -0.6 & 2.9 & 3.1 \\
\hline 1416066_at & $C d 9$ & 5.5 & 0.002 & 1.1 & -2.5 & 2.5 & -3.5 & -3.6 & -3.6 & 0.6 & 1.9 & -1.8 & -2.1 & 3.0 & 4.4 & 3.5 \\
\hline 1456085_x_at & Cd151 & 7.56 & $<0.001$ & -1.2 & -1.1 & -0.7 & -0.7 & -0.9 & -0.6 & -0.3 & 1.4 & -0.2 & -0.3 & 1.8 & 0.8 & 2.1 \\
\hline 1420558_at & Selp & 12.03 & $<0.001$ & -1.0 & -1.2 & -1.9 & -1.6 & -1.5 & -1.7 & -1.1 & -0.9 & -1.7 & -1.6 & 4.3 & 5.7 & 4.1 \\
\hline 1457782_at & $\operatorname{Tln} 1$ & 7.19 & $<0.001$ & -0.7 & -0.4 & -1.4 & -0.3 & -0.8 & -1.0 & 0.9 & 2.3 & -1.5 & -0.5 & 0.8 & 1.4 & 1.3 \\
\hline 1424595_at & F11r & 5.58 & 0.002 & -0.9 & -0.8 & -0.9 & -0.8 & -0.6 & -1.0 & -0.6 & 0.2 & -0.6 & -0.6 & 2.0 & 3.1 & 1.5 \\
\hline 1451097_at & Vasp & 5.24 & $<0.001$ & -0.8 & -1.3 & 0.1 & 0.3 & -0.3 & 0.3 & 0.7 & 0.0 & -0.6 & -1.0 & 0.8 & 1.2 & 0.7 \\
\hline 1418261_at & Syk & 16.04 & $<0.001$ & -2.4 & -2.8 & -2.8 & 2.9 & 2.5 & 2.8 & 1.4 & -1.5 & -2.0 & -3.1 & 1.5 & 1.6 & 1.8 \\
\hline 1455349_at & Rap 1b & 4.63 & $<0.001$ & -0.7 & -0.8 & -1.1 & -0.6 & -1.2 & -1.0 & -0.2 & 2.1 & -0.3 & 0.9 & 0.7 & 0.9 & 1.4 \\
\hline \multicolumn{17}{|c|}{ Heme biosynthesis } \\
\hline 1451675_a_at & Alas2 & 8.85 & $<0.001$ & -3.4 & 0.3 & -0.9 & -2.5 & -3.8 & -3.2 & -1.3 & 4.9 & 4.9 & 4.8 & -2.8 & -0.5 & 3.5 \\
\hline 1424877_a_at & Alad & 8.91 & $<0.001$ & -1.2 & -0.4 & 0.0 & -1.3 & -1.6 & -0.7 & -1.6 & 2.2 & 2.2 & 2.0 & 0.4 & -0.9 & 1.2 \\
\hline 1426475_at & Hmbs & 13.44 & $<0.001$ & -1.2 & -1.0 & -0.4 & -1.5 & -1.1 & -1.1 & -1.1 & 2.6 & 3.4 & 2.7 & -0.8 & -0.9 & 0.5 \\
\hline 1423482_at & Uros & - & - & -0.6 & -0.3 & -0.2 & -0.3 & 0.1 & 0.2 & -0.9 & 0.7 & 1.5 & 0.2 & 0.0 & -0.5 & 0.0 \\
\hline 1417206_at & Urod & 10.87 & $<0.001$ & 0.0 & -0.4 & -0.3 & -1.2 & -0.9 & -1.0 & -0.3 & 1.8 & 1.6 & 1.4 & -0.6 & -0.5 & 0.3 \\
\hline 1422493_at & Cpox & 22.18 & $<0.001$ & -1.6 & -1.2 & -0.2 & -0.5 & -0.8 & -1.0 & -1.5 & 2.7 & 3.1 & 3.2 & -1.0 & -0.7 & -0.4 \\
\hline 1416618_at & Ppox & 4.58 & 0.004 & -0.5 & -0.1 & -0.3 & 0.1 & -0.2 & -0.4 & 0.0 & 0.7 & 1.4 & 0.6 & -0.6 & -0.4 & -0.4 \\
\hline 1418699_s_at & Fech & 8.61 & $<0.001$ & -0.7 & -1.0 & -0.3 & -1.9 & -1.9 & -2.0 & -0.4 & 2.5 & 3.1 & 2.2 & -0.7 & 0.0 & 1.1 \\
\hline \multicolumn{17}{|c|}{ Erythroid and megakaryoblastic transcription factors } \\
\hline \multicolumn{17}{|l|}{ EMk } \\
\hline 1450333_a_at & Gata2 & 7.4 & 0.01 & -1.9 & -1.6 & -1.9 & -1.7 & -1.8 & -1.9 & -1.1 & -0.6 & 2.2 & 0.6 & 3.4 & 3.4 & 2.8 \\
\hline 1423603_at & $Z f p m 1$ (Fog1) & 5.4 & 0.02 & -1.2 & -1.7 & -1.4 & 0.1 & -0.6 & -0.2 & -3.9 & 2.0 & 2.0 & 2.0 & 1.3 & 0.8 & 0.9 \\
\hline 1449389_at & Scl/Tal1 & 20.8 & $<0.01$ & -3.3 & -2.5 & -3.1 & -3.2 & -2.5 & -2.5 & -2.5 & 4.1 & 3.8 & 3.5 & 2.6 & 2.9 & 2.9 \\
\hline 1454086_a_at & Lmo2 & 4.5 & 0.03 & -5.1 & -3.8 & -4.6 & 0.7 & -1.3 & -0.9 & 0.7 & 2.8 & 3.0 & 2.9 & 1.3 & 2.5 & 1.8 \\
\hline 1452001_at & Nfe2 & 8.3 & 0.01 & -4.2 & -3.0 & -3.4 & -3.8 & -3.0 & -3.2 & 1.3 & 3.7 & 3.5 & 3.3 & 2.5 & 3.7 & 2.8 \\
\hline \multicolumn{17}{|l|}{ EMk3 } \\
\hline 1449232_at & Gatal & 4.6 & 0.03 & -1.9 & -1.9 & -2.1 & -2.1 & -2.3 & -2.7 & -1.9 & 4.5 & 4.1 & 4.5 & 0.6 & -1.4 & 2.5 \\
\hline \multicolumn{17}{|l|}{ MkE1 } \\
\hline 1441584_at & Fli1 & 5.3 & 0.1 & -0.2 & -0.4 & -0.5 & 0.7 & 0.6 & 0.5 & 0.7 & 2.6 & -4.8 & -4.9 & 1.8 & 2.4 & 1.6 \\
\hline \multicolumn{17}{|c|}{ Erythroid transcription factors } \\
\hline \multicolumn{17}{|l|}{ EMk3 } \\
\hline 1418600_at & KIf1 & 6.8 & 0.04 & -2.9 & -2.3 & -2.4 & -2.7 & -2.7 & -2.8 & -1.8 & 4.8 & 5.4 & 5.3 & 1.7 & -1.7 & 2.1 \\
\hline 1419311_at & Trim10 & 8.9 & 0.02 & -2.0 & -1.4 & -2.1 & -2.1 & -2.1 & -2.0 & -1.5 & 5.0 & 4.1 & 3.8 & -1.0 & -0.8 & 2.1 \\
\hline \multicolumn{17}{|c|}{ Megakaryoblastic transcription factors } \\
\hline \multicolumn{17}{|c|}{ MkE1 } \\
\hline 1421461_at & $\mathrm{Mpl}$ & 16.1 & $<0.001$ & 0.07 & -1.9 & -1.6 & -2.1 & -2.0 & -2.1 & -2.0 & -1.3 & 1.3 & -1.0 & -1.7 & 4.9 & 4.4 \\
\hline \multicolumn{17}{|l|}{ MkE1 } \\
\hline 1440878_at & Runx 1 & 4.5 & 0.11 & 0.6 & -1.8 & -1.0 & 0.2 & 0.2 & 0.5 & -0.5 & 0.9 & -0.8 & -0.1 & 0.7 & 0.8 & 0.3 \\
\hline
\end{tabular}

* SAM p-value less than 0,001 for every sample

** amplitude of deviation from the mean calculated from the RMA values

According to the megakaryocytic GSE6593 dataset, Fgf3 Jun, Kit, Sfpi, Fes and Bmyc are down-regulated upon megakaryocytic differentiation (Table 2).

When genes within the MkMB signature were compared to GO annotations, one gene class was overrepresented. Many of these genes were membrane receptors and extra-cellular factors known to be expressed by antigen presenting cells (APC) as well as implicated in inflammatory response [19]. For example, Tlr2 (Toll-like receptor 2), Tlr4 (toll-like receptor 4), Syk (Spleen tyrosine kinase) and Ebi3 (Epstein-Barr virus induced gene 3) are part of the Toll-like receptor signaling pathway to respond to microbial stimuli (LPS) and induce inflammation (Table 2). Confirming our data, Tlr2, Tlr4 and Syk are already known to be expressed by the megakaryocytic lineage $[38,39]$. 
Table 2 Genes over-expressed in the megakaryoblastic leukaemias

\begin{tabular}{|c|c|c|c|c|c|c|c|c|c|c|c|c|c|c|c|c|c|c|}
\hline \multirow[t]{2}{*}{ Probeset } & \multirow[t]{2}{*}{ Gene } & \multicolumn{3}{|c|}{ SAM results } & \multicolumn{13}{|c|}{ Leukaemic samples * } & \multirow[t]{2}{*}{$\overline{\text { GSE } 6593}$} \\
\hline & & d-score & p-value & FDR & T1 & T2 & T3 & B1 & B2 & B3 & M & E1 & E2 & E3 & Mk1 & Mk2 & Mk3 & \\
\hline \multicolumn{19}{|c|}{ Genes potentially implicated in the disease ${ }^{* *}$} \\
\hline \multicolumn{19}{|c|}{ Mk } \\
\hline 1443260_at & Meis1 & 12.0 & $<0.001$ & 0.1 & -1.5 & -1.3 & -1.7 & -1.5 & -1.3 & -1.7 & -1.4 & -1.4 & -1.3 & -1.3 & 4.5 & 5.9 & 4.0 & ND \\
\hline 1428647_at & Pbx1 & 10.2 & $<0.001$ & 0.07 & -1.6 & -1.1 & -1.1 & -1.3 & -1.3 & -1.6 & -1.2 & -1.2 & -1.1 & -1.4 & 4.3 & 5.3 & 3.3 & ND \\
\hline 1417155_at & Nmyc & 16.0 & $<0.001$ & 0.08 & -2.0 & -1.6 & -1.9 & -0.7 & -0.6 & -1.2 & -1.6 & -1.8 & -1.5 & -1.9 & 4.8 & 5.6 & 4.4 & NS \\
\hline 1451332_at & Evi3 & 13.0 & $<0.001$ & 0.08 & -1.1 & -1.3 & -1.1 & -1.1 & -1.0 & -0.9 & -0.7 & -0.7 & -0.6 & -0.9 & 3.5 & 3.3 & 2.6 & NS \\
\hline 1441350_at & Fgf3 & 5.4 & 0.002 & 0.12 & -0.7 & -0.7 & -0.6 & -0.6 & -0.7 & -0.8 & -0.6 & -0.4 & -0.6 & -0.5 & 1.3 & 2.9 & 1.9 & $\downarrow$ \\
\hline 1417552_at & Fap & 7.2 & $<0.001$ & 0.09 & -1.7 & -1.6 & -1.7 & -1.8 & -1.7 & -1.7 & -1.7 & -1.5 & -1.6 & -1.4 & 5.9 & 7.0 & 3.6 & ND \\
\hline 1438325_at & Evi1 & 4.5 & 0.005 & 0.16 & -1.8 & -0.9 & -1.4 & -1.7 & -1.7 & -1.4 & -1.8 & -1.1 & -1.4 & -1.5 & 7.3 & 2.4 & 4.8 & ND \\
\hline $\begin{array}{c}\text { 1440964_s_at } \\
\text { MkE1 }\end{array}$ & Cbfa2t3h & 11.0 & $<0.001$ & 0.08 & -0.4 & -0.7 & -1.1 & -0.3 & -0.6 & -0.3 & -0.1 & 0.2 & -0.6 & -0.2 & 1.4 & 1.4 & 1.2 & NS \\
\hline $\begin{array}{l}\text { 1452072_at } \\
\text { MkMB }\end{array}$ & Myct1 & 7.2 & $<0.001$ & 0.07 & -2.0 & -1.7 & -1.7 & -1.6 & -1.5 & -1.6 & -1.4 & 2.0 & -1.1 & 0.6 & 3.0 & 4.5 & 2.5 & NS \\
\hline 1437247_at & FosL2 & 10.3 & $<0.001$ & 0.01 & -0.8 & -0.5 & -0.8 & -0.7 & -0.7 & -0.8 & 1.8 & -0.5 & -0.5 & -0.6 & 1.6 & 1.6 & 0.8 & ND \\
\hline 1417409_at & Jun & 5.1 & $<0.001$ & 0.03 & -0.3 & -1.4 & -3.3 & 1 & 1.1 & 1.4 & 4.1 & -1.3 & -1.5 & -2.3 & 0.8 & 0.8 & 0.91 & $\downarrow$ \\
\hline 1434705_at & Ctbp2 & 15.3 & $<0.001$ & 0.01 & -1.1 & -1.0 & -1.6 & -0.9 & -1.1 & -1.3 & 3.2 & -1.2 & -1.4 & -1.9 & 3.3 & 2.7 & 2.4 & NS \\
\hline 1452514_a_at & Kit & 10.5 & $<0.001$ & 0.01 & -2.2 & -2.1 & -2.2 & -2.2 & -2.3 & 1.2 & 2.8 & -1.7 & -1.6 & -2.2 & 3.8 & 4.6 & 4.0 & $\downarrow$ \\
\hline 1418747_at & Sfpil & 9.9 & $<0.001$ & $<0.01$ & -2.6 & -1.7 & -1.7 & 1.4 & 0.9 & 1.1 & 3.0 & -1.7 & -1.4 & -1.8 & 1.2 & 2.1 & 1.1 & $\downarrow$ \\
\hline 1452410_a_at & Fes & 10.2 & $<0.001$ & $<0.01$ & -2.3 & -1.7 & -1.7 & 1.8 & 0.5 & 1.0 & 3.0 & -1.4 & -2.0 & -1.9 & 1.4 & 2.2 & 1.1 & $\downarrow$ \\
\hline 1428669_at & Bmyc & 5.8 & $<0.001$ & 0.04 & 0.8 & -0.9 & 0.9 & -1.5 & -1.2 & -0.5 & 1.3 & -1.6 & -1.2 & -1.4 & 1.7 & 2.2 & 1.4 & $\downarrow$ \\
\hline 1420710_at & Rel & 5.8 & $<0.001$ & 0.02 & -0.4 & 0.0 & -0.8 & 0.4 & 1.0 & 0.9 & 1.0 & -0.9 & -1.3 & -1.1 & 0.6 & -0.1 & 0.6 & NS \\
\hline \multicolumn{19}{|c|}{ Genes potentially implicated in inflammation response } \\
\hline 1449222_at & Ebi3 & 11.2 & $<0.001$ & 0.01 & -1.4 & -1.3 & -1.2 & -1.4 & -1.2 & -1.3 & 3.6 & -0.7 & -1.1 & -1.6 & 2.2 & 3.1 & 2.23 & $\downarrow$ \\
\hline 1418262_at & Syk & 1.6 & $<0.001$ & $<0.01$ & -2.4 & -2.5 & -2.8 & 2.8 & 2.4 & 2.6 & 1.5 & -1.6 & -2.2 & -2.8 & 1.4 & 1.6 & 1.96 & NS \\
\hline 1419132_at & T/r2 & 6.7 & $<0.001$ & 0.01 & -0.8 & -1.4 & -1.6 & 0.6 & 0.1 & 0.6 & 2.4 & -0.9 & -1.4 & -1.5 & 1 & 2 & 0.9 & $\downarrow$ \\
\hline 1418163_at & TIr4 & 6.3 & $<0.001$ & 0.01 & -1.8 & -1.6 & -1.4 & 0.5 & 1.8 & 2.2 & 2.5 & -1.2 & -0.8 & -1.3 & 0.4 & 0.7 & 0.0 & ND \\
\hline 1456046_at & Clarl & 8.1 & $<0.001$ & $<0.01$ & -2.2 & -3.7 & -4.2 & 4.1 & 3.9 & 4.1 & 3.7 & -2.3 & -2.2 & -4.1 & 0.9 & 0.6 & 1.4 & ND \\
\hline \multicolumn{19}{|c|}{ Genes selected for RT-PCR validation } \\
\hline 1434141_at & Gucyla3 & 18.2 & $<0.001$ & 0.07 & -1.2 & -0.6 & -1.0 & -1.0 & -1.1 & -1.2 & -1.0 & 0.2 & -1.1 & -1.0 & 3.0 & 3.2 & 2.7 & - \\
\hline 1437687_x_at & Fkbp9 & 23.7 & $<0.001$ & 0.07 & -1.4 & -1.3 & -1.6 & -1.3 & -1.3 & -1.3 & -1.1 & -1.0 & -1.0 & -1.1 & 4.1 & 4.6 & 3.9 & NS \\
\hline 1453771_at & Gulp1 & 14.2 & $<0.001$ & 0.07 & -0.7 & -0.7 & -0.5 & -0.6 & -0.9 & -0.9 & -0.9 & -1.0 & -0.9 & -0.9 & 3.1 & 2.6 & 2.3 & - \\
\hline 1448561_at & Ncf2 & 18.5 & $<0.001$ & $<0.01$ & -2.6 & -2.4 & -2.1 & 2.0 & 1.6 & 1.6 & 3.0 & -2.1 & -2.2 & -2.4 & 1.6 & 2.5 & 1.6 & NS \\
\hline 1450333_a_at & Gata2 & 7.4 & $<0.001$ & 0.01 & -2.3 & -2.0 & -2.3 & -2.1 & -2.4 & -1.9 & -1.6 & 0.2 & 2.4 & 1.1 & 3.6 & 4.0 & 3.4 & $\downarrow$ \\
\hline
\end{tabular}

* amplitude of deviation from the mean calculated from the RMA values

** cell cycle/cell growth/development/angiogenesis/DNA repair/transcription regulation

ND (not determined), NS (not significant)

To validate the microarray data, the expression of several megakaryoblastic specific genes was tested by semiquantitative RT-PCR in samples different from those analyzed in the microarray experiments (Table 2 and Figure 2). Within these genes, Kit and Gata2 were tested due to their important roles in haematopoiesis. The other genes were selected for experimentation since they had no prior association with megakaryocytic lineages or with the corresponding leukaemia and also since their function remained poorly studied (Table 2, 'Genes selected for RT-PCR validation'). Within these genes, Gulp1 (Engulfment adaptor PTB domain containing 1) and Gucyla3 (Guanylate cyclase 1, soluble, alpha 3) gave the highest specificity in the RT-PCR experiments with a strong expression in the 3 megakaryoblastic leukaemias (Figure 2). Most of the non-megakaryoblastic leukaemias showed very low or no expression of these genes. Ncf2 (Neutrophil cytosilic factor 2) is highly expressed in the B-cell and megakaryoblastic leukaemias in accordance with the microarray data (Table 2). Fkbp 9 (FK506 binding protein 9) is strongly expressed in the megakaryoblastic leukaemias with a weaker but sustained expression in other types of leukaemias. Gata2 is strongly expressed in the megakaryoblastic leukaemias and to a lower level in 


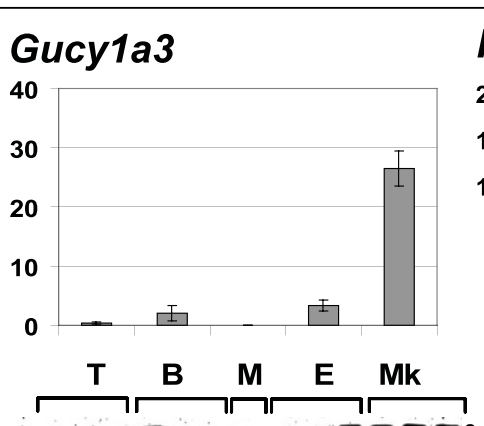

\section{Fkbp9}
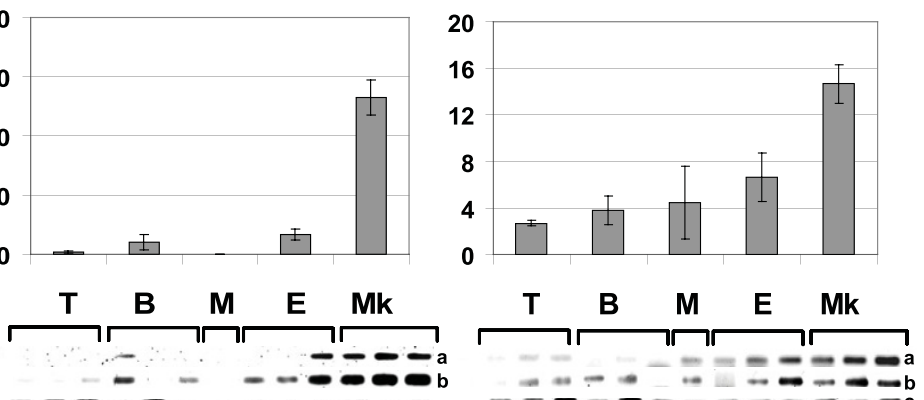

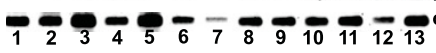

\section{Gulp1}
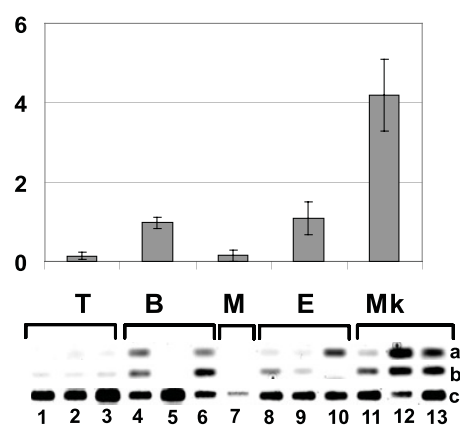

Kit

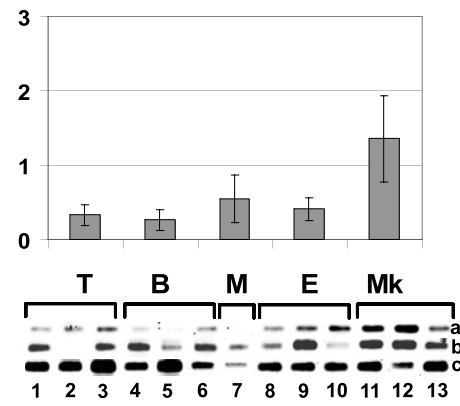

Ncf2
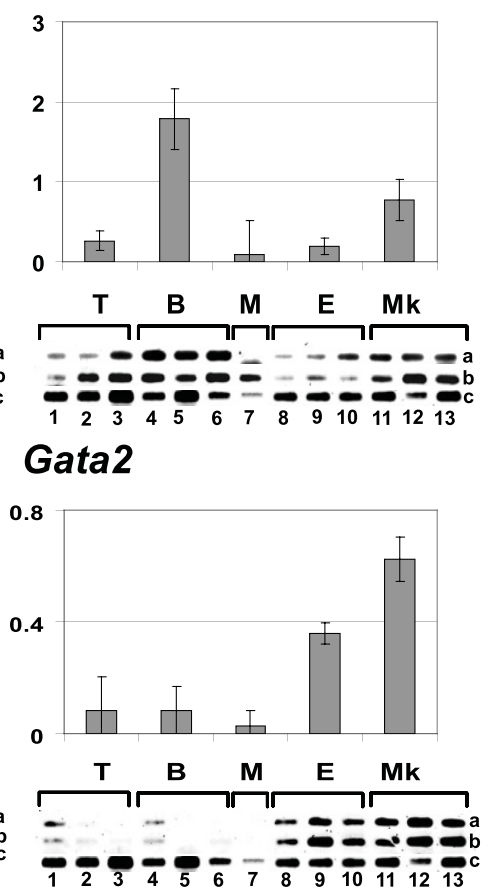

Figure 2 Megakaryoblastic specific genes. Semi-quantitative RT-PCR analysis in 3 T-cell (T, 1-3), 3 B-cell (B, 4-7), 1 myeloid (M, 8), 3 erythroid $(E, 8-10)$ and 3 megakaryoblastic leukaemias (Mk, 11-13). RT-PCRs have been performed in quadruplicate for each sample. Two out of 4 RT-PCR runs are shown for the leukaemic samples (lane a: 25 PCR cycles; lane b: 28 PCR cycles) and 1 out of 4 are shown for the $\beta$-actin internal control (lane c). The histograms represent the quantification of the density of the bands relative to the $\beta$-actin sample including all RT-PCR runs for each type of leukaemia (T, B, M, E, Mk).

the 3 erythroleukaemias. Finally, Kit was amplified in all leukaemias but with the strongest expression in the megakaryoblastic ones (Figure 2).

\section{The erythroid signature}

The results of the erythroid signature were compared to the transcriptome analysis of G1E cells during GATA1 induced differentiation (dataset GSE628, [40]). Our results correlate neatly with this dataset although the Affymetrix Genechip MG-U74A used by Welch and colleagues contains only one third the probes of the MOE 430.2 used in our study. In the Welch et al study, the genes that displayed increased expression during differentiation tended to be under-expressed in the Graffiinduced erythroleukaemias compared to the control sample and vice-versa. This suggests that the Graffiinduced erythroleukaemias are blocked in an earlier stage than the control sample taken from a population of Ter $119^{+} \mathrm{CD} 71^{+}$erythroblasts in the bone marrow. Table 3 provides examples of this correlation between the two studies. For example, Car1 (Carbonic anhydrase 1 ) is over-expressed in the leukaemias in comparison to the control (positive value, column 'E-CE') and its expression decreases during erythroid differentiation 
Table 3 Genes specific to the erythroid leukaemias

\begin{tabular}{|c|c|c|c|c|c|c|c|c|c|c|c|c|c|c|c|c|c|c|c|}
\hline \multirow[t]{2}{*}{ Probeset } & \multirow[t]{2}{*}{ Gene } & \multicolumn{3}{|c|}{ SAM results } & \multicolumn{15}{|c|}{ Leukaemic samples* } \\
\hline & & $\begin{array}{c}\text { d- } \\
\text { score }\end{array}$ & $\begin{array}{c}\mathrm{p}- \\
\text { value }\end{array}$ & FDR & $\mathrm{T} 1$ & $\mathrm{~T} 2$ & T3 & B1 & B2 & B3 & M & E1 & E2 & E3 & Mk1 & MK2 & Mk3 & $\mathrm{E}-\mathrm{CE}$ & G1E \\
\hline \multicolumn{20}{|c|}{ Correlation with the G1E database } \\
\hline 1416193_at & Car1 & 8.2 & $<0.001$ & 0.02 & -3.4 & -2.1 & -3.2 & -3.0 & -3.0 & -3.2 & -2.4 & 6.0 & 5.9 & 1.7 & 1.4 & -2.1 & 3.0 & 1.2 & $\downarrow$ \\
\hline 1422316_at & Gpiba & 12.7 & $<0.001$ & 0.01 & -2.5 & -2.1 & -1.9 & -1.9 & -2.0 & -2.4 & -1.9 & 4.3 & 3.3 & 1.7 & 0.1 & -0.1 & 3.7 & 2.9 & $\downarrow$ \\
\hline 1422817_at & Gp5 & 7.5 & $<0.001$ & 0.03 & -3.6 & -2.3 & -3.0 & -3.0 & -2.9 & -2.8 & -1.9 & 4.5 & 3.6 & 1.7 & 2.4 & 1.6 & 3.4 & 3.8 & $\downarrow$ \\
\hline 1424968_at & 2210023G05Rik & 12.3 & $<0.001$ & 0.01 & -2.4 & -2.3 & -2.1 & -2.2 & -2.2 & -1.9 & -1.9 & 4.4 & 5.5 & 5.1 & -0.2 & -1.1 & 1.4 & 1.3 & $\downarrow$ \\
\hline 1425677_a_at & Ankl & 18.2 & 0.001 & 0.01 & -1.5 & -1.3 & -1.3 & -1.5 & -1.1 & -0.9 & -1.0 & 3.1 & 3.6 & 3.3 & -0.5 & -1.1 & 0.1 & -0.8 & $\uparrow$ \\
\hline 1416464_at & Slc4al & 11.6 & $<0.001$ & 0.02 & -2.3 & -1.4 & -2.0 & -2.4 & -2.7 & -2.0 & -1.2 & 4.7 & 4.6 & 1.7 & -1.8 & 0.2 & 3.2 & -2.4 & $\uparrow$ \\
\hline 1451675_a_at & Alas2 & 11.0 & $<0.001$ & 0.02 & -3.4 & 0.3 & -0.9 & -2.5 & -3.8 & -3.2 & -1.3 & 4.9 & 4.9 & 1.7 & -2.8 & -0.5 & 3.5 & -1.1 & $\uparrow$ \\
\hline 1418699_s_at & Fech & 8.9 & $<0.001$ & 0.02 & -0.8 & -1.0 & -0.7 & -1.4 & -1.7 & -1.5 & -0.5 & 2.2 & 2.5 & 1.7 & -0.2 & 0.0 & 1.3 & -2.4 & $\uparrow$ \\
\hline \multicolumn{20}{|c|}{ Genes potentially implicated in the disease ${ }^{* * *}$} \\
\hline \multicolumn{20}{|c|}{ E } \\
\hline 1417514_at & Ssx2ip & 13.97 & $<0.001$ & 0.01 & -1.1 & -0.8 & -1.4 & -0.3 & -0.3 & -0.5 & -0.5 & 2.8 & 2.7 & 3.0 & -2.4 & -1.4 & 0.3 & 1.1 & $\downarrow$ \\
\hline 1460057_at & Gdf3 & 9.4 & $<0.001$ & 0.01 & -1.3 & -1.2 & -1.0 & -1.3 & -0.9 & -1.0 & 2.0 & 2.2 & 2.4 & 2.8 & -1.3 & -1.3 & -0.1 & 2.9 & NS \\
\hline 1419665_a_at & Nupr1 & 8.7 & $<0.001$ & 0.01 & -1.5 & -1.5 & -1.3 & -1.3 & -1.3 & -1.7 & 0.3 & 3.9 & 2.5 & 3.3 & -0.9 & -0.6 & 0.2 & 4.0 & - \\
\hline 1443969_at & Irs2 & 6.5 & $<0.001$ & 0.02 & 0.1 & -0.1 & -1.5 & -0.2 & -0.4 & 0.4 & -1.0 & 1.1 & 2.1 & 1.4 & -1.2 & -0.5 & -0.2 & 1.2 & $\uparrow$ \\
\hline 1417165_at & $M b d 2$ & 17.38 & $<0.001$ & 0.01 & -0.7 & -0.1 & -0.4 & 0.0 & -0.1 & -0.3 & -0.6 & 1.3 & 1.3 & 1.3 & -0.6 & -0.7 & -0.2 & 0.9 & - \\
\hline 1449256_a_at & Rab11a & 10.59 & $<0.001$ & 0.01 & -1.0 & -0.3 & -1.2 & -0.6 & -0.6 & -0.3 & -0.4 & 1.7 & 1.7 & 1.3 & -0.3 & -0.1 & 0.2 & 1.7 & - \\
\hline 1417396_at & Podxl & 6.5 & $<0.001$ & 0.02 & -0.8 & -0.9 & -1.0 & -1.0 & -0.9 & -0.7 & -1.0 & 1.3 & 1.6 & 1.7 & 1.6 & 0.2 & -0.1 & 2.4 & NS \\
\hline \multicolumn{20}{|l|}{ EMk3 } \\
\hline 1422737_at & Ncoa3 & 4.1 & 0.003 & 0.10 & -0.3 & -1.2 & -0.1 & -0.5 & -0.4 & 0.3 & -0.3 & 1.5 & 0.4 & 0.8 & 0.0 & -0.7 & 0.6 & 2.2 & NS \\
\hline 1435458_at & Pim 1 & 5.4 & $<0.001$ & 0.06 & -1.0 & -1.3 & -2.0 & -0.6 & -0.4 & -0.4 & -0.2 & 1.5 & 1.5 & 1.0 & 0.1 & 0.9 & 0.9 & 0.6 & $\uparrow$ \\
\hline \multicolumn{20}{|c|}{ Genes selected for RT-PCR validation } \\
\hline 1449232_at & Gata1 & 4.58 & $<0.001$ & 0.03 & -1.9 & -1.9 & -2.1 & -2.1 & -2.3 & -2.7 & -1.9 & 4.5 & 4.1 & 4.5 & 0.6 & -1.4 & 2.5 & 0.4 & $\uparrow$ \\
\hline 1425571_at & Slamf1 & 9.9 & $<0.001$ & 0.02 & -1.3 & -1.6 & -1.7 & -1.2 & -1.6 & -1.5 & -2.0 & 4.1 & 3.0 & 1.7 & -0.3 & -1.2 & 1.9 & 4.8 & - \\
\hline 1418493_a_at & Snca & 10.2 & $<0.001$ & 0.02 & -3.3 & -0.2 & -1.0 & -2.5 & -3.2 & -1.8 & -1.5 & 4.6 & 4.2 & 1.7 & -1.0 & -0.7 & 2.7 & -2.6 & $\uparrow$ \\
\hline 1418061_at & Ltbp2 & 15 & $<0.001$ & 0.01 & -0.7 & -0.7 & -0.7 & -0.7 & -0.8 & -0.7 & -0.9 & 2.2 & 1.5 & 1.7 & -0.5 & -0.8 & 1.4 & 2.0 & NS \\
\hline 1419069_at & Rabgef1 & 25.0 & $<0.001$ & 0.01 & -0.5 & -0.8 & -0.4 & -0.9 & -1.3 & -1.2 & -0.8 & 2.2 & 2.3 & 2.3 & -0.4 & -0.4 & -0.1 & 4.8 & - \\
\hline 1427357_at & Cda & 25.0 & $<0.001$ & 0.01 & -1.5 & -1.6 & -1.6 & -1.7 & -1.8 & -0.6 & -1.3 & 4.3 & 4.8 & 4.9 & -1.6 & -1.7 & -0.7 & 6.0 & - \\
\hline 1417152_at & Btbd14a & 9.5 & $<0.001$ & 0.02 & -0.6 & -0.9 & -0.9 & -0.9 & -0.8 & -0.9 & -0.5 & 2.3 & 1.5 & 1.7 & -0.4 & -0.4 & 1.0 & 2.3 & NS \\
\hline
\end{tabular}

(descending arrow, column 'G1E'). Alas2 (Aminolevulinic acid synthase 1), involved in the heme biosynthesis, is under-expressed in the leukaemias in comparison to the control and its expression increases during erythroid differentiation.

Table 3 presents a summary of the erythroid specific genes over-expressed in comparison to the control sample and potentially implicated in the disease but the complete data are readily available [19]. Within these genes, Gdf3 (Growth differentiation factor 3), Podxl (Podocalyxin-like), Nupr1 (Nuclear protein 1), Pim1 (Proviral integration site 1) and Isr2 (Insulin receptor substrate 2) are known to be regulated by erythropoietin [41-43]. The oncogene Pim1 was found rearranged in Friend helper MuLV-induced erythroleukaemias and Graffi-induced leukaemias [36,44]. Ssx2ip (Synovial sarcoma, X breakpoint 2 interacting protein) was found over-expressed in some AML patients and is expressed by K562 erythroid cells [45]. Rab11a (RAB11a, member RAS oncogene family) was reported to regulate the recycling of the transferrin receptor [46]. This protein interacts with Evi5 [47] and has a potential role in cancer [48]. The oncogene Ncoa3 (Nuclear receptor coactivator 3 ) is over-expressed in numerous cancer types such as breast, prostate, ovarian, gastric, pancreatic and colorectal cancers [49].

Many genes have not yet been reported in relation to erythroid leukaemias and several others have a still unknown function and some of them have been selected for RT-PCR validation (Table 3 and Figure 3). Gata1 was tested due to its important role in haematopoiesis (Figure 3). Among the 7 tested erythroid genes (Table 3, 'Genes selected for RT-PCR validation'), both $C d a$ (Cytidine deaminase) and Ltbp2 (Latent transforming growth factor beta binding protein 2) showed a very high and 


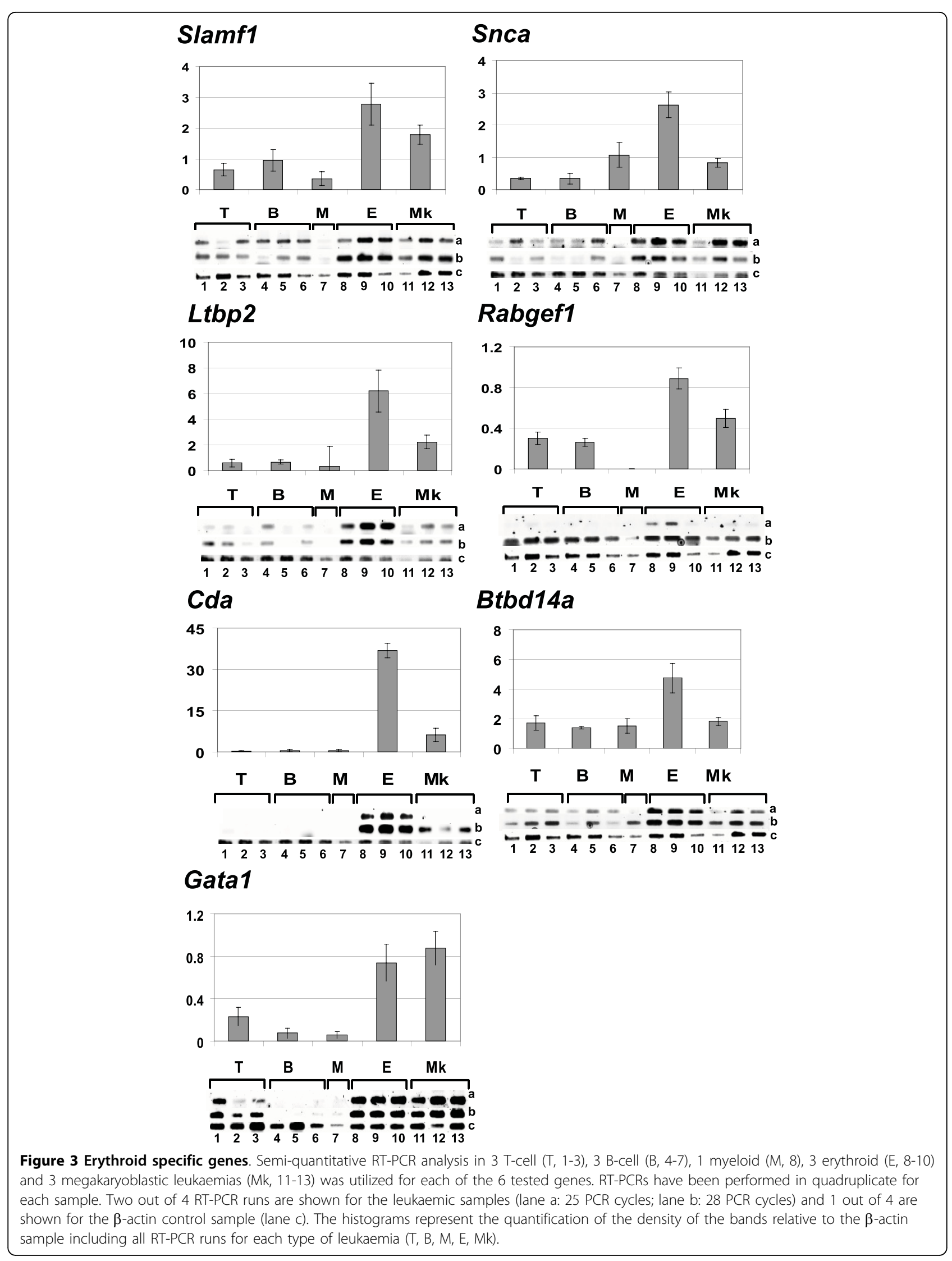


specific expression in the 3 erythroleukaemias (Figure 3). Slamf1 (Signaling lymphocytic activation molecule family member 1), Snca (Synuclein alpha) and Btbd14a (BTB/ $P O Z$ domain containing $14 A$ ) are higher expressed in the erythroleukaemias and lower in the megakaryoblastic leukaemias but were also amplified in other types of leukaemias. Rabgef1 is specifically expressed in the erythroleukaemias at 25 PCR cycles (lane a) but was amplified in all samples at 28 PCR cycles (lane b). Gata1 is equally highly expressed in the erythroid and in the megakaryoblastic leukaemias (Figure 3).

\section{RT-PCR validation in a Friend virus murine} erythroleukaemia cell line

The expression of the erythroid and megakaryoblastic specific transcripts validated by RT-PCR (Figures 2 and
3) was further assessed on a different erythroid model (Figure 4). The erythroleukaemia cell line HB22.2 has been derived from a leukaemia induced by the Friend Murine Leukaemia virus (F-MuLV) and it presents a very immature erythroid phenotype $\left(\mathrm{Kit}^{+} \mathrm{CD} 71^{+} \mathrm{Ter} 119^{-}\right.$ CD41-) ([17]). The 6 erythroid genes (Slamf1, Snca, Ltbp2, Rabgef1, Cda and Btbd14a) are expressed in HB22.2 but the intensity of the Ltbp 2 and Btdb14a bands were weaker (Figure 4A). In accordance with our expectations, the megakaryoblastic genes, Ncf2, Gucyla3 and Gulp1, could not be amplified. Fkbp 9 is the only megakaryoblastic gene that gave a weak signal in this erythroid cell line. Indeed, $F k b p 9$ showed the strongest erythroid amplification in the RT-PCR validation experiment (Figure 2). Thus, these results show that, despite the close relationship between erythroid and

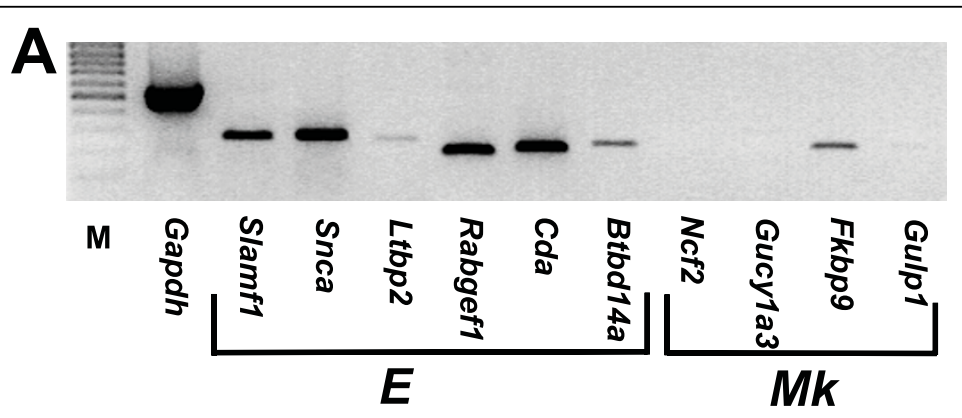

B

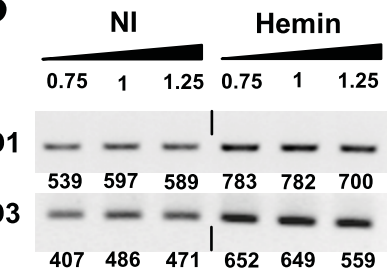

Hba
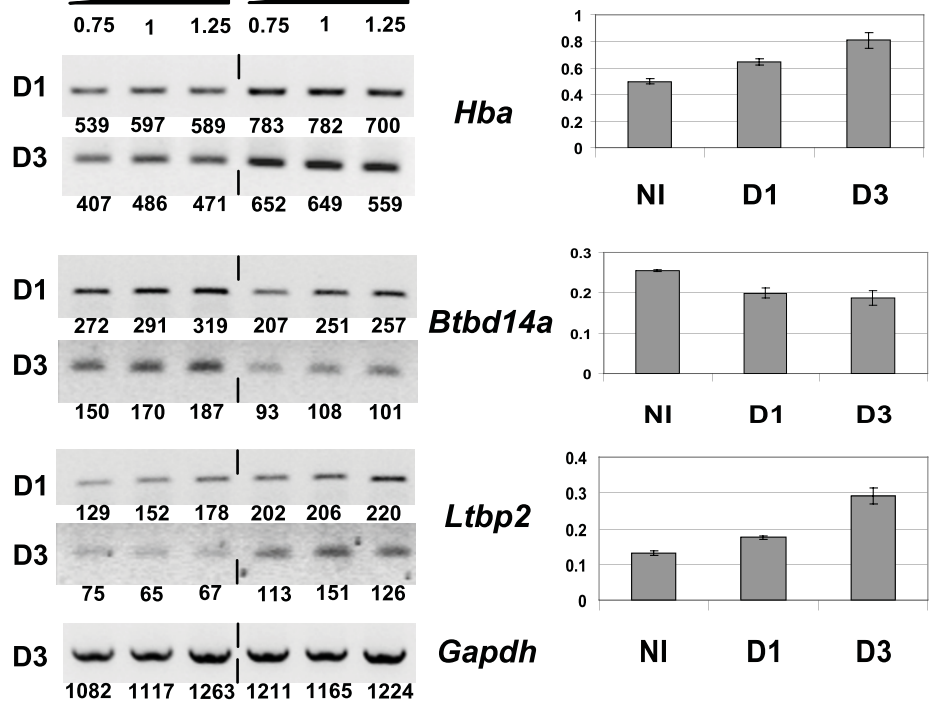

108211171263121111651224

Figure 4 Expression of the erythroid and megakaryoblastic specific genes in the murine erythroleukaemia cell line HB22.2 during hemin-induced differentiation. (A) Semi-quantitative RT-PCR analysis of 6 erythroid specific genes (E) and 4 megakaryoblastic specific genes (Mk). The first lane (M) indicates the low-range DNA marker. (B) Hemin-induced differentiation assay of HB22.2 cells. Semi-quantitative RT-PCR analysis of Hba as differentiation control, Btbd14a and Ltbp2 was performed in non-induced (NI) and induced (Hemin) cells at day 1 (D1) and day 3 (D3) following hemin addition. GAPDH expression was used as internal control. Three independent RT-PCR reactions were performed on each sample using increasing amount of the RT reaction ( 0.75 volume, 1 volume, 1.25 volume). The band intensity was measured and indicated below each band. On the right half of the figure, the histograms show the average results of the band intensities relative to the Gapdh control sample. 
megakaryoblastic leukaemias, this experiment's design enabled us to find genes that can distinguish these 2 types of murine leukaemias from each other.

We then induced HB22.2 differentiation with hemin and tested the expression of the erythroid specific genes at different time-points (Figure 4). Integration of F-MuLV upstream of Fli-1 is shown to block differentiation of this cell line [17]. However, these cells are able to undergo differentiation with hemin associated induction of alpha globin (Figure 4B). Among the 6 erythroid genes tested, both Btbd14a and Ltbp 2 showed reproducible changes with a decrease and an increase with differentiation, respectively (Figure 4B). The increased expression of $L t b p 2$ indicates that it likely plays a role in mature erythroid cells whereas Btbd14a is likely to play a role in immature erythroid cells and this correlates well with a putative oncogenic role for this gene.

\section{Validation in human leukaemic cell lines}

The proteins encoded by these erythroid and megakaryoblastic specific genes have high homologies with their human counterparts. This makes it likely that these human and murine proteins have the same functional role. Gene expression was first tested in 2 human erythroid-like cell lines, HEL and K562, a human B-cell leukaemia cell line, TK6, and a human T-cell leukaemia cell line, Jurkat (Figure 5A). Because HEL and K562 are known to harbour mixed myeloid lineage phenotype, the genes were further tested in 2 human megakaryoblastic cell lines, MEG-01 and CMK, and 1 erythroid cell line LAMA-84 (Figure 5B).

The results show that all tested erythroid and megakaryoblastic specific genes were amplified in some or all of the cell lines confirming their expression in human erythroid or megakaryoblastic cell lines. Moreover, several were also amplified in the lymphoid lines TK6 and/ or in Jurkat. RABGEF1 and BTBD14A were the most ubiquitous genes with a strong amplification in lymphoid and non-lymphoid cell lines. GULP1 and SNCA were the most specific to the non-lymphoid lineage with no expression in TK6 or Jurkat cell lines.

\section{Viral integrations in the megakaryoblastic leukaemias}

We also identified retroviral integration sites (RIS) in the 3 megakaryoblastic leukaemias (Mk1-3) in order to search for genes that may have contributed to the oncogenic transformation. Several RIS were amplified, cloned and sequenced in these 3 tumors (11 in Mk1, 5 in Mk2 and 10 in Mk3) (Table 4). No common integration sites (CIS) that could clearly indicate the contribution to the oncogenic events were found. Therefore, the results were compared to the retroviral tagged cancer gene database (RTCGD, [50]) that compiles the RIS identified in different murine cancer models (underlined in Table 4). Genes identified in multiple screens have a high probability of involvement in oncogenic transformation. Eleven genes near the RIS were found in the RTCGD (underlined in Table 4). Some of these genes, such as Ccnd 1 and $M y c$, are largely known to be involved in leukaemia. Foxf1 is a transcription factor known to regulate the megakaryocytic integrin $\beta 3$ (CD61) [51]. Interestingly, Kit and Gata 2 are also part of RIS. The presence of the RIS near Kit in Mk1 and near Gata2 in Mk3 has been validated by PCR in the sorted leukaemic megakaryoblastic population (not shown). Two other genes, Irf8 and Itga 1 targeted by a RIS (Table 4) are also of interest: Irf8 is not included in the RTCGD database but is a known CIS [52] and the ITGA1 locus is repressed by methylation during megakaryopoiesis in humans [53].

\section{Discussion}

\section{Characterization of genes specific to erythro- and} megakaryoblastic leukaemias

Patient survey studies revealed that erythroleukaemias represent an average of $5 \%$ of all cases of acute myeloid leukaemias [3-5] and megakaryoblastic leukaemias have an incidence of approximately $1 \%$ in adults and $5-10 \%$ in children [6,7]. However, the overall survival rate is extremely poor and ranges from $6 \%$ to $17 \%$ [3,7]. Children suffering from Down Syndrome are an exception as they have a higher risk of developing megakaryoblastic leukaemias but respond better to therapy [54]. Acute erythro- and megakaryoblastic leukaemias are less studied than the more frequent types of leukaemias. Thus, genes involved in the development of these leukaemias remain insufficiently elucidated.

Our experimental design is based on the comparison of non-lymphoid versus lymphoid murine leukaemias and provides the whole picture of genes specific to these 2 groups and subgroups. The sole comparison of the non-lymphoid leukaemias and their respective controls without including the lymphoid group would not have provided such a dataset. Therefore, numerous genes not described previously or uncharacterized emerged from this study. We estimated that, within the identified gene signatures, there are oncogenes directly implicated in the disease and also genes related to the normal commitment of the cells toward the erythro- or megakaryoblastic lineages. To determine which genes are potential oncogenes, we first compared the erythroleukaemias to the erythroid control samples and to the study of Welch and colleagues [40]. The comparison with the Welch's study enabled to assess the differentiation state of the leukaemias and the control. Consequently, we could assume that the genes under-expressed in comparison to the control 


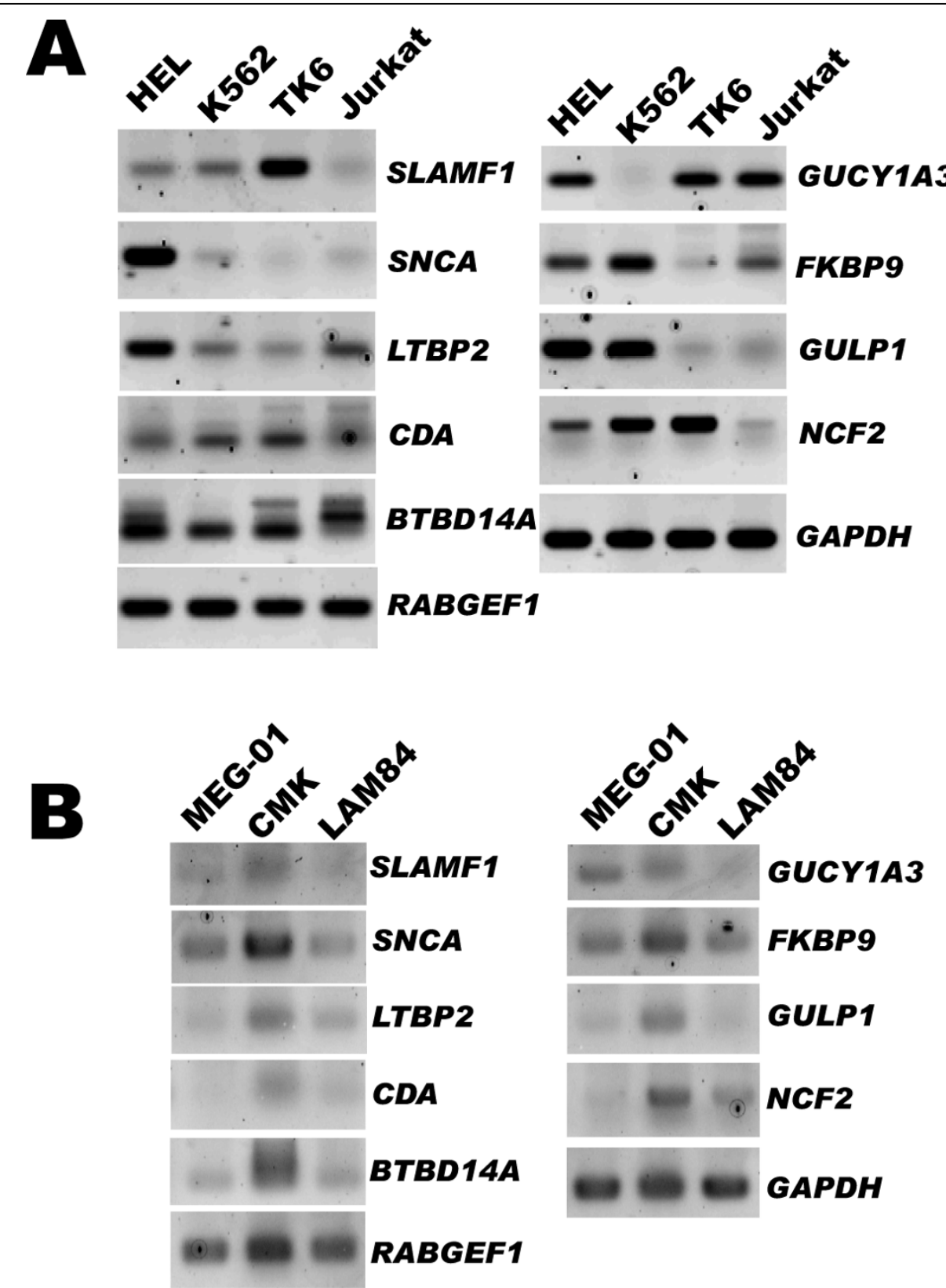

Figure 5 Validation in human cell lines. (A) RT-PCR analysis in the erythroid-like human cell lines K562 and HEL, the B- cell lymphoblastic cell line TK6 and the T-cell leukaemia cell line Jurkat. (B) RT-PCR analysis in the human megakaryoblastic cell lines MEG-01 and CMK and the human erythroid cell line LAMA-84. The left and right parts of each panel correspond to genes identified in the erythro- and megakaryoblastic leukaemias, respectively. GAPDH was used as internal control.

are late stage genes and that oncogenes are more likely to be within the over-expressed genes. We validated this hypothesis with Ltbp2 and Btbd14a in a differentiation assay in the HB22.2 erythroid cell line. Second, to gain more insights into the function of the megakaryoblastic genes and in the absence of a control sample, we compared our list of genes to the study of Shivdasani and colleagues [37]. The comparison with the studies of Welch for the erythroid leukaemias [40] and of
Shivadasani [37] for the megakaryoblastic leukaemias provides valuable information about the behaviour of the genes during normal differentiation. However, their respective microarray chips contained less probesets than ours and we could not perform the comparison on the whole dataset. Therefore, further experiments are required to identify the unknown role played by these genes in erythro- and megakaryoblastic leukaemias. 
Table 4 Graffi-virus integration sites in the megakaryoblastic leukaemias

\begin{tabular}{|c|c|c|c|c|c|c|c|c|c|c|c|}
\hline \multirow[t]{2}{*}{ Sample } & \multirow[t]{2}{*}{ Chromosome } & \multirow[t]{2}{*}{ Genome } & \multicolumn{4}{|c|}{ Upstream genes* } & \multirow{2}{*}{$\begin{array}{c}\text { Integra-tion } \\
\text { within a gene }\end{array}$} & \multicolumn{4}{|c|}{ Downstream genes* } \\
\hline & & & gene 1 & $\mathrm{~kb}$ & gene 2 & $\mathrm{~kb}$ & & gene 1 & $\mathrm{~kb}$ & gene 2 & $\mathrm{~kb}$ \\
\hline \multirow[t]{11}{*}{ Mk1 } & $1 \mathrm{D}$ & 93018002 & Gm817 & 17 & Lrrfipl & 60 & $\underline{R a m p 1}^{* *}$ & Ube2f & 95 & Scly & 130 \\
\hline & $1 \mathrm{G} 2$ & 153451217 & Rnf2 & 188 & 1190005F20Rik & 230 & Niban & Edem3 & 92 & Q8K3Do & 199 \\
\hline & $4 \mathrm{~B} 1$ & 41816941 & 2310028 H24Rik & 133 & 1700066J25Rik & 138 & Dnaic1 & Cntfr & 29 & Dent3 & 86 \\
\hline & $5 \mathrm{E} 1$ & 75741720 & Pdgfra & 216 & Gsh2 & 382 & - & $\mathrm{Kit}^{* *}$ & 114 & $K d r$ & 472 \\
\hline & $6 \mathrm{~F} 3$ & 128801887 & Klrbib & 10 & $\mathrm{Clec} 2 \mathrm{~h}$ & 159 & - & Clec21 & 50 & Klrbif & 208 \\
\hline & $6 \mathrm{G} 1$ & 135264443 & Gsg1 & 61 & Hebp 1) & 130 & - & Pbp2 & 10 & Dynlt1 & 50 \\
\hline & 11B4 & 70471623 & $\underline{P f n}^{* *}$ & 0.8 & Rnf167 & 4 & - & Eno3 & 1.7 & Spag7 & 8.2 \\
\hline & 11B5 & 80139013 & $\overline{R h o t 1}$ & 55 & Rnf135 & 123 & Rhbd13 & Zfp207 & 60 & Psmd11 & 105 \\
\hline & 15D3 & 62283939 & Pvt1 & 211 & $\underline{M y c}^{* *}$ & 463 & & - & & - & \\
\hline & $15 \mathrm{~F} 2$ & 95582212 & $D b \times 2$ & 100 & Nell2 & 225 & - & - & & Tmem16f & 36 \\
\hline & $16 \mathrm{~B} 3$ & 33700976 & Hegl & 13 & S/c12a8 & 118 & - & Muc13 & 12 & $\underline{\operatorname{ltg} 65}{ }^{* *}$ & 48 \\
\hline \multicolumn{12}{|l|}{ Mk2 } \\
\hline & $1 \mathrm{E} 4$ & 132543823 & Pfkb2 & 0.4 & $C 4 b p$ & 54 & - & Yod1 & 0.8 & AA986890 & 1 \\
\hline & $6 \mathrm{A3}$ & 25759728 & Pot $1 a$ & 14 & Grp37 & 120 & - & - & & - & \\
\hline & $8 \mathrm{E} 1$ & 123703449 & Irf8 & 81 & Cox4i1 & 149 & - & $\underline{F o x f 1}^{* *}$ & 269 & Mthfsd & 280 \\
\hline & $12 \mathrm{C} 1$ & 52786246 & Hectd1 & 120 & EG544864 & 35 & - & Heatr5a & 11 & 6530401NO4Rik & 124 \\
\hline & $13 \mathrm{D} 2.3$ & 116255725 & Pelo & 46 & Itga1 & 33 & - & - & & - & \\
\hline \multicolumn{12}{|l|}{ Mk3 } \\
\hline & $1 C 5$ & & Glrp1 & 146 & Spp2 & 230 & - & Arl14C & 161 & Sh3bp4 & 413 \\
\hline & $1 F$ & 139621937 & - & & & & - & Ptprc & 257 & Atp6v1g3 & 466 \\
\hline & $2 \mathrm{H} 3$ & 165618991 & Prkcbp ${ }^{* *}$ & 43 & Eya2 & 156 & - & Ncoa3 & 65 & Sulf2 & 146 \\
\hline & $5 \mathrm{~B} 1$ & 43941 & Rheb & 23 & Cryng & 83 & - & $\underline{\operatorname{Prkag}}^{* *}$ & 20 & 1500035N22Rik & 144 \\
\hline & $6 \mathrm{D} 2$ & 88086902 & Rpn 1 & 16 & EG434064 & 115 & - & Gata2 $^{* *}$ & 72 & Dnajb8 & 100 \\
\hline & 7B4 & 45356428 & Bax & 21 & Flt1 & 28 & Dhdh & $\overline{N u c b} 1$ & 4 & Tulp2 & 25 \\
\hline & 7F5 & 144856850 & $\mathrm{CCndl}^{* *}$ & 107 & Oraov1 & 167 & - & $\operatorname{Tpcn2)}$ & 167 & Mrgprf & 253 \\
\hline & $13 \mathrm{~A} 1$ & 3830652 & Calm13 & 27 & & & - & Calm4 & 6 & Calm5 & 22 \\
\hline & $14 C 3$ & 53491694 & Prmt5 & 20 & Rem2 & 57 & - & D14Ertd500e & 4 & $J u b$ & 31 \\
\hline & $19 \mathrm{~A}$ & 4301566 & Ankrd13d & 18 & Ssh3 & 32 & Adrbk1** & Fbx/13 & 15 & FBXL13 & 15 \\
\hline
\end{tabular}

* the 2 most proximal genes located at a maximum distance of $500 \mathrm{~kb}$ upstream $\left(5^{\prime}\right)$ or downstream $\left(3^{\prime}\right)$ of the integration site

** genes present in the RTCGD database

\section{Erythroid and megakaryoblastic genes}

Erythroid and megakaryoblastic lineages, emerging from the same bipotent progenitor, are very closely related [11] and, as confirmed by our study, several transcription factors are commonly expressed. This strengthens the hypothesis that a very fine tuning of these factors influences the commitment toward the erythroid or megakaryocytic lineages.

Our microarray data indicate that Gata1, Gata2, Fog1, $\mathrm{Scl}$ and $\mathrm{Lmo} 2$ are expressed both in the Graffi-induced erythro- and megakaryoblastic leukaemias (Table 1). They are known to act on the promoter of their target as multimeric complexes. Our study highlights that PU.1 (Sfpi1), Ctbp2, Cbfa2t3h (Eto2), Evi1 and Runx1 have a strong megakaryoblastic pattern. PU.1 is a known determinant of erythroid versus megakaryoblastic differentiation and the Gata2 protein acts on PU.1 [55]. The $\mathrm{Cbfa} 2 \mathrm{t} 3 \mathrm{~h}$ protein binds to the multimeric complex formed by Gata1, Fog1, Scl and Lmo2 and is known to repress the transcription of the target genes. The corepressor Ctbp2 is known to bind to Evi1 and Fog1 [56]. Runx1 cooperates with Gata1 during megakaryocytic commitment $[22,23]$ and the Runx1-Evil fusion protein leads preferentially to the development of megakaryoblastic leukaemias in transgenic mice [57]. In a model of in vitro differentiation, Evil is strongly induced and sustained upon thrombopoietin treatment of $\mathrm{CD} 34^{+}$cells in a pattern very similar to Gata 2 and PU.1 but only weakly upon erythropoietin treatment [58]. Great evidence indicates that Evi1 is a direct activating target of Gata2 [59]. Thus, our study reinforces the importance of these genes in the megakaryoblastic leukaemias.

\section{RT-PCR validated megakaryoblastic genes}

The specific megakaryoblastic expression of several genes with poorly elucidated physiological roles was validated by 
RT-PCR. Our study reports for the first time Gucyla3, Gulp1 and Fkbp 9 as being specific to megakaryoblastic leukaemias. The function of these genes, related to the normal development or transformation of megakaryocytic cells, has yet to be elucidated. Insight into their physiological roles can be provided by their already known functions in other cell types. Gucyla3 is known to heterodimerize with Gucy1b3, which gene is also specific to the Graffiinduced megakaryoblastic leukaemias. The Gucy1a3/b3 complex produces cGMP after activation by nitric oxide (NO) itself produced by the NADPH oxidase from reactive oxygen species. As expected, $N c f 2$ and other components of the NADPH oxidase $(N c f 1, N c f 4, C y b b)$ are specifically over-expressed in the Graffi-induced megakaryoblastic leukaemias (Figure 2 and not shown). In human cancerous glioma cell lines, it is hypothesized that GUCY1a3/b3 may be responsible for VEGF over-expression resulting in an increased amount of $\mathrm{NO}$ [60]. NO is also known to play a role in platelet activation [61]. Gulp1 could be involved in the intracellular vesicular trafficking [62] which is of high importance in megakaryocytes for transporting the molecules in the storage organelles and during proplatelet formation. Fkbp 9 is poorly studied and this present study reports its expression for the first time in cells of haematopoietic origin. It is strongly expressed in our megakaryoblastic leukaemias, in human non-lymphoid leukaemias HEL, K562, CMK, Meg-01 and LAMA84, and to a lesser extent, in the murine erythroid leukaemias and cell line.

\section{RT-PCR validated erythroid genes}

The selected erythroid genes with poorly elucidated physiological roles were Slamf1, Snca, Ltbp2, Rabgef1, Cda and Btbd1a. Slamf1 is known to be expressed by activated lymphocytes but not yet identified in relation to erythroid leukaemias. The expression of Slamf1 in Friend virusinduced erythroleukaemic cell line HB22.2 confirms the Graffi model. The gene was recently revealed as a marker of haematopoietic stem cells distinguishing these cells from more differentiated progenitors [63]. Snca has already been reported in erythrocytes $[64,65]$. Its overexpression in the control sample and its increased expression during erythroid differentiation (G1E dataset, Table 3 ) indicate that it may be implicated in normal erythroid cells function. We did not observe a significant increase during HB22.2 induced differentiation. $L t b p 2$ is strongly expressed in our erythroleukaemias and increases significantly during differentiation. It shows a non-lymphoid expression pattern in the tested human cell lines and is identified in relation to haematopoietic cells for the first time. Some studies suggest a role for $L t b p 2$ in cell adhesion and in cell migration [66]. Rabgef1 has never been reported in relation to erythroid lineage or leukaemia and the encoded protein is known to interact with Rab5, Rab21 or Rab22 [67]. Rab22a is indeed specifically over-expressed in the 3 tested erythroleukaemias (not shown). RAB proteins are implicated in the intra-cellular vesicular traffic regulation and Rabgef1 is expressed in mast cells where it acts on Kit internalization [68]. Even though Rabgef1 expression pattern is more erythroid, it was amplified in all other Graffi-induced leukaemias and in all the tested human cell lines, indicating its ubiquitous expression in haematopoietic cells. $C d a$, responsible for resistance to chemotherapy treatment, is highly expressed in our erythroleukaemias, in HB22.2, K562 and HEL. The GEO database shows that $C D A$ is up-regulated during the differentiation of human $\mathrm{CD} 34^{+}$cells toward the erythroid lineage (NCBI GEO, GSE4655). As of this day, Btbd14a has never been studied. It is highly expressed in the Graffiinduced erythroleukaemias and in HB22.2. Finally, $B t b d 14 a$ appears ubiquitously expressed in the haematopoietic system. The BTB/POZ domain of Btb14a is present in many oncogenes involved in the development of leukaemia and is often found at the N-terminus of transcription factors. Thus, this gene is particularly interesting to further study as it shows a decreased expression during HB22.2 induced differentiation and could represent a potential oncogene.

\section{The MkMB Signature}

Numerous genes were commonly over-expressed in the megakaryoblastic, the myeloid leukaemias and/or the Bcell leukaemias. These genes are, in most cases, already known to be expressed by cells implicated in innate immunity. Platelets function is too often considered limited to blood coagulation and formation of thrombosis but some studies now emphasize that the platelets' role is underestimated in innate immunity and inflammation response [39,69-72]. Upon activation, platelets can release microbicidal proteins, interleukins that trigger a general inflammation response and chemokines that recruit immune cells such as leukocytes. Pathogens such as bacteria and lentiviruses can be ingested by platelets [73]. The MkMB signature seems to reflect partly the complexity of the platelet function. Only very few examples are shown in Table 2 but the complete list is available in the supplementary data [19]. The unique design of this gene expression study that compared different types of leukaemias highlights this signature.

\section{Retroviral integration and genes potentially implicated in the onset of the disease}

The analysis of retroviral integration enables the identification of genes that may be responsible for malignant transformation. In this study, we screened the 3 megakaryoblastic leukaemias for viral integration sites as oncogenic transformation events leading to megakaryoblastic leukaemias remain unknown. No CIS were identified but some genes in the RTCGD have drawn our 
attention due to their known functions. Within these genes, Kit and Gata2 are of particular interest as accumulating evidences point at their role in megakaryopoiesis and megakaryoblastic leukaemias.

Gata 2 was recently reported for the first time as a common integration site in leukaemias induced by the MOL4070LTR retrovirus in the NHD13 mouse [74]. In vitro studies showed that Gata2 over-expression redirects the haematopoietic differentiation from the macrophage lineage toward the erythroid or the megakaryocytic lineages or from the erythroid toward the megakaryocytic lineage [55,75]. The importance of Gata2 on megakaryopoiesis was also demonstrated in a differentiation study in which this gene is strongly induced and sustained upon thrombopoietin treatment of $\mathrm{CD} 34^{+}$cells but only weakly induced upon erythropoietin treatment [58]. The authors made the interesting hypothesis that GATA2 might repress the expression of the erythroid markers in maturing megakaryocytic cells since its activation inhibits erythroid differentiation in some systems.

Kit is involved in many cancers and is regulated by the SCL complex (Gata1/2, SCL, Lmo2) in haematopoietic cells [76]. More evidence begins to emerge for its role in very early stages of megakaryopoiesis $[77,78]$ and in megakaryoblastic leukaemias $[79,80]$. Bourquin et al. reported increased levels of KIT, GATA2 and MYC in DS AMKL cells harbouring a GATA1 mutation compared to non-DS AMKL cells. They hypothesized that the mutated GATA1 in DS AMKL cells failed to repress the expression of these 3 genes [79].

The 3 megakaryoblastic leukaemias express very high levels of Kit and Gata2. We hypothesize that the viral integrations may block the repression of these genes by continuously activating the transcription or inhibiting the binding of repressor molecules. Kit and Gata2 levels normally decrease during megakaryocytic differentiation (Table 2 'GSE6593'). These 2 genes, affected by the retroviral integration, would send continuous signals of proliferation and survival to the cell. The analysis of a larger sample of Graffi-induced megakaryoblastic leukaemias would be required to prove more efficiently the involvement of Gata2 and Kit in this particular type of leukaemia.

\section{Conclusions}

In this report, we compared the gene profiles of the erythro- and megakaryoblastic leukaemias induced by the Graffi virus. Our study identifies genes that are highly expressed in the Graffi-induced erythro- and megakaryoblastic leukaemias. The complete dataset of this study is readily available (GSE12581 and [19]). Within the data, numerous genes have not yet been assigned with a known function and some of them could be used as markers for specific types of leukaemias and even the target of new therapies. We selected and RT-PCR validated genes those functions in normal cells are poorly characterized. For the majority, their expression in these lineages is shown for the first time and further functional characterization will surely complement the knowledge of erythroid and megakaryocytic lineages.

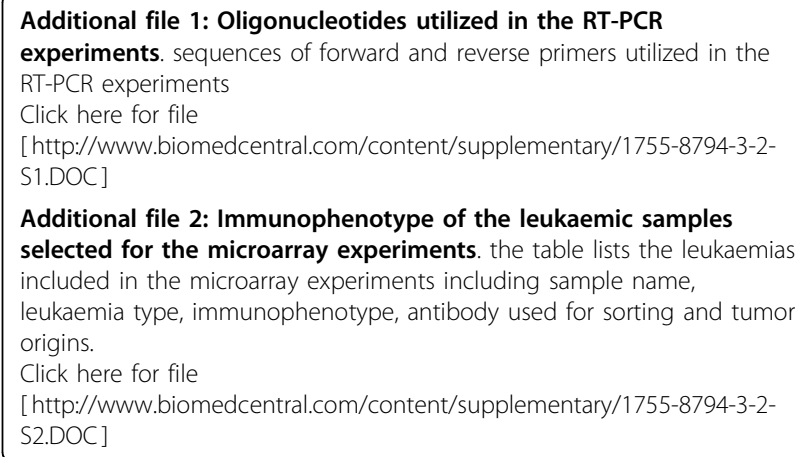

\section{Acknowledgements}

We thank André Ponton, Michal Blazejczyk and Mathieu Miron from McGill University and Genome Quebec Innovation Centre (Montreal, Canada) for their help with the design and analyses of the microarray experiments. This work was supported by Canadian Institutes of Health Research grants MOP37994 (ER) and MOP-84460 (YBD).

\section{Author details}

${ }^{1}$ Laboratoire de Biologie Moléculaire, Département des Sciences Biologiques, Centre BioMed, Université du Québec à Montréal, Case Postale 8888 Succursale Centre-ville, Montréal, QC, H3C-3P8, Canada. ${ }^{2}$ Sunnybrook Health Sciences Center, 2075 Bayview Ave. S223B, Toronto. ON, M4N 3M5, Canada.

\section{Authors' contributions}

W designed and performed the microarray, RT-PCR, differentiation assay and cloning of the viral insertion sites experiments, analyzed and interpreted the data, and wrote the manuscript. PL performed the RT-PCR experiments on the human haematopoietic cell lines. DPSO optimized the protocol for the cloning of viral integration sites. YBD provided the HB22.2, K562 and HEL cell lines and critically revised the manuscript. ER guided the project and wrote the manuscript. All authors read and approved the final manuscript.

\section{Competing interests}

The authors declare that they have no competing interests.

Received: 17 August 2009

Accepted: 26 January 2010 Published: 26 January 2010

\section{References}

1. Bennett JM, Catovsky D, Daniel MT, Flandrin G, Galton DA, Gralnick HR, Sultan C: Criteria for the diagnosis of acute leukemia of megakaryocyte lineage (M7). A report of the French-American-British Cooperative Group. Ann Intern Med 1985, 103(3):460-462.

2. Bennett JM, Catovsky D, Daniel MT, Flandrin G, Galton DA, Gralnick HR, Sultan C: Proposals for the classification of the acute leukaemias. FrenchAmerican-British (FAB) co-operative group. British journal of haematology 1976, 33(4):451-458.

3. Colita A, Belhabri A, Chelghoum Y, Charrin C, Fiere D, Thomas X: Prognostic factors and treatment effects on survival in acute myeloid leukemia of M6 subtype: A retrospective study of 54 cases. Annals of Oncology 2001, 12:451-455.

4. Wells AW, Bown N, Reid MM, Hamilton PJ, Jackson GH, Taylor PR: Erythroleukaemia in the north of England: a population based study. Journal of Clinical Pathology 2001, 54:608-612. 
5. Domingo-Claros A, Larriba I, Rozman M, Irriguible D, Vallespi T, Aventin A, Ayats R, Milla F, Sole F, Florensa $L$, et al: Acute erythroid neoplastic proliferations. A biological study based on 62 patients. Haematologica 2002, 87(2):148-153.

6. Rogelio Paredes-Aguilera LR-GNL-SRAT: Biology, clinical, and hematologic features of acute megakaryoblastic leukemia in children. American Journal of Hematology 2003, 73:71-80.

7. Garderet L, Labopin M, Gorin NC, Polge E, Baruchel A, Meloni G, Ortega J, Vossen J, Bunjes D, Leverger $G$, et al: Hematopoietic stem cell transplantation for de novo acute megakaryocytic leukemia in first complete remission: a retrospective study of the European Group for Blood and Marrow Transplantation (EBMT). Blood 2005, 105(1):405-409.

8. Park S, Picard F, Dreyfus F: Erythroleukemia: a need for a new definition. Leukemia 2002, 16(8):1399-1401.

9. Linari S, Vannucchi AM, Ciolli S, Leoni F, Caporale R, Grossi A, Pagliai G, Santini V, Paoletti F, Ferrini PR: Coexpression of erythroid and megakaryocytic genes in acute erythroblastic (FAB M6) and megakaryoblastic (FAB M7) leukaemias. British journal of haematology 1998, 102(5):1335-1337.

10. Debili N, Coulombel L, Croisille L, Katz A, Guichard J, Breton-Gorius J, Vainchenker W: Characterization of a bipotent erythro-megakaryocytic progenitor in human bone marrow. Blood 1996, 88(4):1284-1296.

11. Nakorn TN, Miyamoto T, Weissman IL: Characterization of mouse clonogenic megakaryocyte progenitors. Proceedings of the National Academy of Sciences of the United States of America 2003, 100(1):205-210.

12. Voisin V, Barat $C$, Hoang $T$, Rassart E: Novel insights into the pathogenesis of the Graffi murine leukemia retrovirus. J Virol 2006, 80(8):4026-4037.

13. Blazejczyk M, Miron M, Nadon R: FlexArray: A statistical data analysis software for gene expression microarrays. Genome Quebec, Montreal, Canada, URL http://genomequebec.mcgill.ca/FlexArray. 2007.

14. Eisen MB, Spellman PT, Brown PO, Botstein D: Cluster analysis and display of genome-wide expression patterns. Proceedings of the National Academy of Sciences of the United States of America 1998, 95(25):14863-14868.

15. Tamayo P, Slonim D, Mesirov J, Zhu Q, Kitareewan S, Dmitrovsky E, Lander ES, Golub TR: Interpreting patterns of gene expression with selforganizing maps: methods and application to hematopoietic differentiation. Proceedings of the National Academy of Sciences of the United States of America 1999, 96(6):2907-2912.

16. Tusher VG, Tibshirani R, Chu G: Significance analysis of microarrays applied to the ionizing radiation response. Proceedings of the National Academy of Sciences of the United States of America 2001, 98(9):5116-5121.

17. Wong KS, Li YJ, Howard J, Ben-David Y: Loss of p53 in F-MuLV inducederythroleukemias accelerates the acquisition of mutational events that confers immortality and growth factor independence. Oncogene 1999, 18(40):5525-5534.

18. Mikkers H, Allen J, Knipscheer P, Romeijn L, Hart A, Vink E, Berns A: Highthroughput retroviral tagging to identify components of specific signaling pathways in cancer. Nature genetics 2002, 32(1):153-159.

19. Voisin V, Rassart E: Erythroid and megakaryoblastic leukemias induced by the murine retrovirus Graffi Gene expression profiling MOE 430.2 GEO: GSE12581 Additional analyses and Downloadable excel filesURL: http:// www.biomed.uqam.ca/rassart/microarray.html. 2009.

20. Hao X, Shin MS, Zhou JX, Lee CH, Qi CF, Naghashfar Z, Hartley JW, Fredrickson TN, Ward JM, Morse HC: Histologic and molecular characterizations of megakaryocytic leukemia in mice. Leuk Res 2006, 30(4):397-406, Epub 2005 Oct 2010.

21. Hamlett I, Draper J, Strouboulis J, Iborra F, Porcher C, Vyas P: Characterization of megakaryocyte GATA1-interacting proteins: the corepressor ETO2 and GATA1 interact to regulate terminal megakaryocyte maturation. Blood 2008, 112(7):2738-2749.

22. Nucifora G, Laricchia-Robbio L, Senyuk V: EVI1 and hematopoietic disorders: history and perspectives. Gene 2006, 368:1-11.

23. Kilbey A, Alzuherri H, McColl J, Cales C, Frampton J, Bartholomew C: The Evi1 proto-oncoprotein blocks endomitosis in megakaryocytes by inhibiting sustained cyclin-dependent kinase 2 catalytic activity. British journal of haematology 2005, 130(6):902-911.

24. Bond HM, Mesuraca M, Carbone E, Bonelli P, Agosti V, Amodio N, De Rosa G, Di Nicola M, Gianni AM, Moore MA, et al: Early hematopoietic zinc finger protein (EHZF), the human homolog to mouse Evi3, is highly expressed in primitive human hematopoietic cells. Blood 2004, 103(6):2062-2070.
25. Hentges KE, Weiser KC, Schountz T, Woodward LS, Morse HC, Justice MJ: Evi3, a zinc-finger protein related to EBFAZ, regulates EBF activity in Bcell leukemia. Oncogene 2005, 24(7):1220-1230.

26. Hu L, Sham JS, Xie D, Wen JM, Wang WS, Wang Y, Guan XY: Up-regulation of fibroblast growth factor 3 is associated with tumor metastasis and recurrence in human hepatocellular carcinoma. Cancer Lett 2007, 252(1):36-42.

27. van Lohuizen M, Breuer M, Berns A: N-myc is frequently activated by proviral insertion in MuLV-induced T cell lymphomas. Embo J 1989, 8(1):133-136

28. Yancopoulos GD, Nisen PD, Tesfaye A, Kohl NE, Goldfarb MP, Alt FW: N-myc can cooperate with ras to transform normal cells in culture. Proc Natl Acad Sci USA 1985, 82(16):5455-5459.

29. Cheng JD, Valianou M, Canutescu AA, Jaffe EK, Lee HO, Wang H, Lai JH, Bachovchin WW, Weiner LM: Abrogation of fibroblast activation protein enzymatic activity attenuates tumor growth. Mol Cancer Ther 2005, 4(3):351-360

30. Rogulski KR, Cohen DE, Corcoran DL, Benos PV, Prochownik EV: Deregulation of common genes by c-Myc and its direct target, MT-MC1. Proceedings of the National Academy of Sciences of the United States of America 2005, 102(52):18968-18973.

31. Yates KE, Gasson JC: Role of c-Fes in normal and neoplastic hematopoiesis. Stem cells (Dayton, Ohio) 1996, 14(1):117-123.

32. Emilia G, Donelli A, Ferrari S, Torelli U, Selleri L, Zucchini P, Moretti L, Venturelli D, Ceccherelli G, Torelli G: Cellular levels of mRNA from c-myc, c-myb and c-fes onc-genes in normal myeloid and erythroid precursors of human bone marrow: an in situ hybridization study. British journal of haematology 1986, 62(2):287-292.

33. Fox AH, Liew C, Holmes M, Kowalski K, Mackay J, Crossley M: Transcriptional cofactors of the FOG family interact with GATA proteins by means of multiple zinc fingers. The EMBO journal 1999, 18(10):2812-2822.

34. Hromas R, Orazi A, Neiman RS, Maki R, Van Beveran C, Moore J, Klemsz M: Hematopoietic lineage- and stage-restricted expression of the ETS oncogene family member PU.1. Blood 1993, 82(10):2998-3004.

35. Doubeikovski A, Uzan G, Doubeikovski Z, Prandini MH, Porteu F, Gisselbrecht S, Dusanter-Fourt I: Thrombopoietin-induced expression of the glycoprotein Ilb gene involves the transcription factor PU.1/Spi-1 in UT7-Mpl cells. The Journal of biological chemistry 1997, 272(39):24300-24307.

36. Denicourt C, Edouard E, Rassart E: Oncogene activation in myeloid leukemias by Graffi murine leukemia virus proviral integration. J Virol 1999, 73(5):4439-4442.

37. Chen Z, Hu M, Shivdasani RA: Expression analysis of primary mouse megakaryocyte differentiation and its application in identifying stagespecific molecular markers and a novel transcriptional target of NF-E2. Blood 2007, 109(4):1451-1459.

38. Andonegui $G$, Kerfoot SM, McNagny K, Ebbert KV, Patel KD, Kubes P: Platelets express functional Toll-like receptor-4. Blood 2005, 106(7):2417-2423.

39. Cognasse F, Hamzeh H, Chavarin P, Acquart S, Genin C, Garraud O: Evidence of Toll-like receptor molecules on human platelets. Immunology and cell biology 2005, 83(2):196-198.

40. Welch JJ, Watts JA, Vakoc CR, Yao Y, Wang H, Hardison RC, Blobel GA, Chodosh LA, Weiss MJ: Global regulation of erythroid gene expression by transcription factor GATA-1. Blood 2004, 104(10):3136-3147.

41. Fang J, Menon M, Kapelle W, Bogacheva O, Bogachev O, Houde E, Browne S, Sathyanarayana P, Wojchowski DM: EPO modulation of cellcycle regulatory genes, and cell division, in primary bone marrow erythroblasts. Blood 2007, 110(7):2361-2370.

42. Sathyanarayana P, Menon MP, Bogacheva O, Bogachev O, Niss K, Kapelle WS, Houde E, Fang J, Wojchowski DM: Erythropoietin modulation of podocalyxin and a proposed erythroblast niche. Blood 2007, 110(2):509-518.

43. Sathyanarayana P, Dev A, Fang J, Houde E, Bogacheva O, Bogachev O, Menon M, Browne S, Pradeep A, Emerson C, et al: EPO receptor circuits for primary erythroblast survival. Blood 2008, 111(11):5390-5399.

44. Dreyfus F, Sola B, Fichelson S, Varlet $P$, Charon $M$, Tambourin $P$, Wendling $F$, Gisselbrecht S: Rearrangements of the Pim-1, c-myc, and p53 genes in Friend helper virus-induced mouse erythroleukemias. Leukemia 1990, 4(8):590-594. 
45. Breslin A, Denniss FA, Guinn BA: SSX2IP: an emerging role in cancer. Biochemical and biophysical research communications 2007, 363(3):462-465.

46. Ren M, Xu G, Zeng J, De Lemos-Chiarandini C, Adesnik M, Sabatini DD: Hydrolysis of GTP on rab11 is required for the direct delivery of transferrin from the pericentriolar recycling compartment to the cell surface but not from sorting endosomes. Proceedings of the National Academy of Sciences of the United States of America 1998, 95(11):6187-6192.

47. Westlake CJ, Junutula JR, Simon GC, Pilli M, Prekeris R, Scheller RH, Jackson PK, Eldridge AG: Identification of Rab11 as a small GTPase binding protein for the Evi5 oncogene. Proceedings of the National Academy of Sciences of the United States of America 2007, 104(4):1236-1241.

48. Palmieri D, Bouadis A, Ronchetti R, Merino MJ, Steeg PS: Rab11a differentially modulates epidermal growth factor-induced proliferation and motility in immortal breast cells. Breast cancer research and treatment 2006, 100(2):127-137

49. Yan J, Tsai SY, Tsai MJ: SRC-3/AIB1: transcriptional coactivator in oncogenesis. Acta pharmacologica Sinica 2006, 27(4):387-394.

50. Akagi K, Suzuki T, Stephens RM, Jenkins NA, Copeland NG: RTCGD: retroviral tagged cancer gene database. Nucleic acids research 2004, 32 Database: D523-527.

51. Malin D, Kim IM, Boetticher E, Kalin TV, Ramakrishna S, Meliton L, Ustiyan V, Zhu $X$, Kalinichenko W: Forkhead box F1 is essential for migration of mesenchymal cells and directly induces integrin-beta3 expression. Molecular and cellular biology 2007, 27(7):2486-2498.

52. Ma SL, Sorensen AB, Kunder S, Sorensen KD, Quintanilla-Martinez L, Morris DW, Schmidt J, Pedersen FS: The Icsbp locus is a common proviral insertion site in mature B-cell lymphomas/plasmacytomas induced by exogenous murine leukemia virus. Virology 2006, 352(2):306-318.

53. Cheli Y, Kanaji S, Jacquelin B, Chang M, Nugent DJ, Kunicki TJ: Transcriptional and epigenetic regulation of the integrin collagen receptor locus ITGA1-PELO-ITGA2. Biochimica et biophysica acta 2007, 1769(9-10):546-558.

54. Hitzler JK, Zipursky A: Origins of leukaemia in children with Down syndrome. Nat Rev Cancer 2005, 5(1):11-20.

55. Kitajima K, Tanaka M, Zheng J, Yen H, Sato A, Sugiyama D, Umehara H, Sakai $E$, Nakano T: Redirecting differentiation of hematopoietic progenitors by a transcription factor, GATA-2. Blood 2006, 107(5):1857-1863.

56. Chinnadurai G: CtBP, an unconventional transcriptional corepressor in development and oncogenesis. Molecular cell 2002, 9(2):213-224.

57. Maki K, Yamagata T, Asai T, Yamazaki I, Oda H, Hirai H, Mitani K: Dysplastic definitive hematopoiesis in AML1/EVI1 knock-in embryos. Blood 2005, 106(6):2147-2155

58. Terui K, Takahashi Y, Kitazawa J, Toki T, Yokoyama M, Ito E: Expression of transcription factors during megakaryocytic differentiation of CD34+ cells from human cord blood induced by thrombopoietin. The Tohoku journal of experimental medicine 2000, 192(4):259-273.

59. Yuasa H, Oike $Y$, Iwama A, Nishikata I, Sugiyama D, Perkins A, Mucenski ML, Suda T, Morishita K: Oncogenic transcription factor Evi1 regulates hematopoietic stem cell proliferation through GATA-2 expression. The EMBO journal 2005, 24(11):1976-1987.

60. Saino M, Maruyama T, Sekiya T, Kayama T, Murakami Y: Inhibition of angiogenesis in human glioma cell lines by antisense RNA from the soluble guanylate cyclase genes, GUCY1A3 and GUCY1B3. Oncology reports 2004, 12(1):47-52.

61. Battinelli $E$, Willoughby SR, Foxall $T$, Valeri CR, Loscalzo J: Induction of platelet formation from megakaryocytoid cells by nitric oxide. Proceedings of the National Academy of Sciences of the United States of America 2001, 98(25):14458-14463.

62. Kiss RS, Ma Z, Nakada-Tsukui K, Brugnera E, Vassiliou G, McBride HM, Ravichandran KS, Marcel YL: The lipoprotein receptor-related protein-1 (LRP) adapter protein GULP mediates trafficking of the LRP ligand prosaposin, leading to sphingolipid and free cholesterol accumulation in late endosomes and impaired efflux. The Journal of biological chemistry 2006, 281(17):12081-12092.

63. Kiel MJ, Yilmaz OH, Iwashita T, Yilmaz OH, Terhorst C, Morrison SJ: SLAM family receptors distinguish hematopoietic stem and progenitor cells and reveal endothelial niches for stem cells. Cell 2005, 121(7):1109-1121.

64. Nakai M, Fujita M, Waragai M, Sugama S, Wei J, Akatsu H, OhtakaMaruyama C, Okado H, Hashimoto M: Expression of alpha-synuclein, a presynaptic protein implicated in Parkinson's disease, in erythropoietic lineage. Biochemical and biophysical research communications 2007, 358(1):104-110.

65. Scherzer CR, Grass JA, Liao Z, Pepivani I, Zheng B, Eklund AC, Ney PA, Ng J, McGoldrick M, Mollenhauer B, et al: GATA transcription factors directly regulate the Parkinson's disease-linked gene alpha-synuclein. Proceedings of the National Academy of Sciences of the United States of America 2008, 105(31):10907-10912.

66. Vehvilainen P, Hyytiainen M, Keski-Oja J: Latent Transforming Growth Factor- $\beta$-binding Protein 2 Is an Adhesion Protein for Melanoma Cells. The Journal of Biochemical Chemistry 2003, 278:24705-24713.

67. Mattera R, Tsai YC, Weissman AM, Bonifacino JS: The Rab5 guanine nucleotide exchange factor Rabex-5 binds ubiquitin (Ub) and functions as a Ub ligase through an atypical Ub-interacting motif and a zinc finger domain. The Journal of biological chemistry 2006, 281(10):6874-6883.

68. Kalesnikoff J, Rios EJ, Chen C-C, Nakae S, Zabel BA, Butcher EC, Tsai M, Tam S-Y, Galli SJ: RabGEF1 regulates stem cell factor/c-Kit-mediated signaling events and biological responses in mast cells. Proceedings of the National Academy of Sciences of the United States of America 2006, 103:2659-2664

69. Weyrich AS, Zimmerman GA: Platelets: signaling cells in the immune continuum. Trends in immunology 2004, 25(9):489-495.

70. Elzey BD, Sprague DL, Ratliff $\mathrm{TL}$ : The emerging role of platelets in adaptive immunity. Cellular immunology 2005, 238(1):1-9.

71. Sprague DL, Sowa JM, Elzey BD, Ratliff TL: The role of platelet CD154 in the modulation in adaptive immunity. Immunologic research 2007, 39(13):185-193.

72. von Hundelshausen P, Weber C: Platelets as immune cells: bridging inflammation and cardiovascular disease. Circulation research 2007 100(1):27-40.

73. Tanaka M, Aze Y, Fujita T: Adhesion molecule LFA-1/ICAM-1 influences on LPS-induced megakaryocytic emperipolesis in the rat bone marrow. Veterinary pathology 1997, 34(5):463-466.

74. Slape C, Hartung H, Lin YW, Bies J, Wolff L, Aplan PD: Retroviral insertional mutagenesis identifies genes that collaborate with NUP98-HOXD13 during leukemic transformation. Cancer research 2007, 67(11):5148-5155.

75. Ikonomi $P$, Rivera CE, Riordan M, Washington $G$, Schechter AN, Noguchi CT: Overexpression of GATA-2 inhibits erythroid and promotes megakaryocyte differentiation. Experimental hematology 2000, 28(12):1423-1431.

76. Lecuyer $\mathrm{E}$, Hoang $\mathrm{T}$ : SCL: from the origin of hematopoiesis to stem cells and leukemia. Experimental hematology 2004, 32(1):11-24.

77. Antonchuk J, Hyland CD, Hilton DJ, Alexander WS: Synergistic effects on erythropoiesis, thrombopoiesis, and stem cell competitiveness in mice deficient in thrombopoietin and steel factor receptors. Blood 2004, 104(5):1306-1313.

78. Zeuner A, Signore M, Martinetti D, Bartucci M, Peschle C, De Maria R: Chemotherapy-induced thrombocytopenia derives from the selective death of megakaryocyte progenitors and can be rescued by stem cell factor. Cancer research 2007, 67(10):4767-4773

79. Bourquin JP, Subramanian A, Langebrake C, Reinhardt D, Bernard O, Ballerini P, Baruchel A, Cave H, Dastugue N, Hasle H, et al: Identification of distinct molecular phenotypes in acute megakaryoblastic leukemia by gene expression profiling. Proceedings of the National Academy of Sciences of the United States of America 2006, 103(9):3339-3344.

80. Toki T, Kanezaki R, Adachi S, Fujino H, Xu G, Sato T, Suzuki K, Tauchi H, Endo $\mathrm{M}$, Ito $\mathrm{E}$ : The key role of stem cell factor/KIT signaling in the proliferation of blast cells from Down syndrome-related leukemia. Leukemia 2009, 23(1):95-103.

\section{Pre-publication history}

The pre-publication history for this paper can be accessed here:http://www biomedcentral.com/1755-8794/3/2/prepub

doi:10.1186/1755-8794-3-2

Cite this article as: Voisin et al: Gene profiling of the erythro- and megakaryoblastic leukaemias induced by the Graffi murine retrovirus. BMC Medical Genomics 2010 3:2 